\title{
Formalisation and use of competencies for industrial performance optimisation: a survey
}

\author{
$\underline{\text { Xavier Boucher }^{1}}$, Eric Bonjour ${ }^{2}$, Bernard Grabot ${ }^{3}$ \\ ${ }^{1}$ ENSMSE-G2I, 158 cours Fauriel, 42100 Saint Etienne, France \\ (e-mail:boucher@emse.fr, Tel + 33-4-77 42-01-33, Fax + 33-4-77 42-66-66) \\ ${ }^{2}$ LAB - UMR CNRS 6596 - ENSMM - U.F.C - 25 rue Alain Savary 25000 Besançon, France \\ ${ }^{3}$ LGP-ENIT, 47 Avenue d'Azereix, BP 1629, F-65016 Tarbes Cedex, France
}

\begin{abstract}
For many years, industrial performance has been implicitly considered as deriving from the optimisation of technological and material resources (machines, inventories,...), made possible by centralized organisations. The topical requirements for reactive and flexible industrial systems have progressively reintroduced the human workforce as the main source of industrial performance. Making this paradigm operational requires the identification and careful formalisation of the link between human resource and industrial performance, through concepts like skills, competencies or know-how. This paper provides a general survey of the formalisation and integration of competence-oriented concepts within enterprise information systems and decision systems, aiming at providing new methods and tools for performance management.
\end{abstract}

Keywords: Competence model, performance, information and decision systems, enterprise modelling.

\section{Introduction}

For many years, the industrial context has been characterised by an increasing need of flexibility and reactivity. Consideration of the pure notion of "optimisation" is no longer sufficient for improvements of industrial performance. Performance becomes more dependent on management of change and innovation, both for product and organisation. In such a context, human workforce appears as a natural source of flexibility and reactivity, like automation and centralised planning were natural sources of productivity optimisation in previous periods. This evolution leads one to re-consider some process management activities or functions, traditionally technology-centred. Indeed this "new" way of considering human resource, not only as a resource among others but as the main source of performance, requires a more precise formalisation of concepts like competence or skills, in order to be able to efficiently link people, as source of performance, to process activities.

The paper emphasises the notion of competence; however, in the remainder of the text, we use this concept to cover several notions referred to in academic research as skills, abilities or even capabilities. The expression "individual competence" is used to deal with the competence of a person, the expression "collective competence" is used to deal with the competence emerging from a group of persons and the expression "global competence" is used to describe the organisational ability of an enterprise. Putting the focus on the notion of competence can be explained by what Zarifian calls the "competence model" [1]: a new way to consider the relationships between the workforce, the enterprise and the managers, associated with a new vision of the performance and the organisation of work, as well as new forms of management and decision-making. For instance, at the level of human resource management, the organisational model has shifted from the old and 
Final draft paper published in : Computers in industry, Volume 58, Issue 2, February 2007, Pages 98-117

restrictive notion of employee "qualifications", to a broader notion of employee "competencies": this new concept allows a deeper description of the real skills and a much more flexible management of human resources.

If the "competency model" is ever more in use in industry, decisional tools and methods available at different levels of management have not yet fully incorporated the deep impact of such change. This paper tackles the topical issue of how to integrate competence-oriented concepts within enterprise information systems and decision systems, so as to provide managers with the good decision support. In that context, the central issue becomes how to deal with internal and external competencies in an efficient and reactive way, so as to determine where in the organisation people can be the best sources of performance enhancement.

This research area is at the crossroads of several disciplines: socio-human sciences, aiming at understanding what competence is and how it grows or decreases, managerial sciences aiming at integrating the "competency model" within strategic analysis, but also industrial engineering (including production management and computer sciences) aiming at integrating the concept of competence within information systems, as a basis for performance analysis and for the development of decision support systems. These fields are of course in interaction but their positioning is clearly differentiated by the objectives of their respective communities and by the scientific methods and paradigms in use in each domain. The current paper will only focus on the domain of industrial engineering and aims at providing a survey on how competence-related concepts are modelled and formalised in the scientific literature dealing with the improvement of the industrial performance, and what perspectives can be expected to better integrate these concepts in a wide range of existing industrial engineering methods.

To provide a reference framework, Section 2 aims at positioning the concepts of competence and performance within industrial processes. The possible causality relations between competence and performance are then analysed, and the three following sections review papers dealing with the integration of these concepts in information or decision support systems. For that purpose, three complementary fields have been selected, for which industrial engineering methods specifically require addressing the competence paradigm more intensively, and thus where a large amount of academic work can be found. Sections 3 and 4 deal with complementary steps in product industrialisation, respectively design management and production management. Section 5 is dedicated to "competence in the management of distributed organisation", giving thus an organisational view transversal to the various steps of the product life-cycle. Finally, new perspectives emerging from that broad survey are drawn in section 6 . 
Final draft paper published in : Computers in industry, Volume 58, Issue 2, February 2007, Pages 98-117

\section{2- Connection between competence, performance and processes}

\subsection{Towards a competence-oriented management of process performance}

The aim of this section is to clarify the link between competence and performance, so that the connection between systems dealing with management of competence and management of processes is established. Indeed, the link between competence and performance has been underlined in many scientific articles, at multiple levels of decision and according to various points of view, often corresponding to distinct disciplines.

The industrial context emphasised in the introduction has positioned human factors, and more specifically skills and competencies, at the heart of industrial performance. Managerial theories can help us to identify the relation between the management of performances and the management of competencies. Indeed, in the traditional process-oriented approach initially developed by Porter [2], the enterprise is considered as a goodsand-services production system. Firms' performance directly depends on the management of value creation processes: the performance is generated by the efficacy of goods-and-services production processes ${ }^{1}$, associated with external factors of market positioning. Complementary approaches have highlighted some limits of that orientation: the "Resource Based View" theory states that a large part of the competitive advantage lies in the internal assets of a firm, among which competencies play an important part [3], [4], [5]. From that point of view, the direct management of process performances is not sufficient and competitiveness lies also in the development of the internal potential of competencies.

Figure 1, extracted from [6], suggests a necessary interrelationship between the two previous points of view. Indeed, according to the focus chosen, the enterprise can be considered either as a goods-and-services production system or as a competence production system. Thus, these two points of view merely lead to two complementary models of the same system. The interaction between them can be explained by referring to performance: the performance of the goods-and-services production system is generated by the competencies available, depending on two main factors: (i) the levels of competencies available and (ii) the ability to allocate and coordinate competencies along business processes.

These two factors induce two main means of action for a better use of competencies to enhance performance. On one side, one deals with a descriptive and static view of the competencies available at a given moment where the performance improvement is based on a better use of available competencies. On the other side, one takes into account a dynamic view of the competencies, and the performance improvement can be based on an

\footnotetext{
1 "Production system" is used herein in a broad sense, not limited to manufacturing processes but covering all the life cycle of the product.
} 
Final draft paper published in : Computers in industry, Volume 58, Issue 2, February 2007, Pages 98-117

increase of the available potential of competencies. Of course, both types of competence-based improvement actions are to be combined with more classical actions to enhance industrial performance.

A crucial step towards the implementation of this competence paradigm within performance management systems is to define the concepts and models required to introduce competence in firms' information and decision systems. This survey paper addresses this topical question, with a restrictive focus on industrial engineering methods: research on models used to make an operational use of the notion of competence within information systems, development of decision support systems and methods, and computer-based tools useful in an industrial context. Before coming to the management of processes in sections 3, 4 and 5, the first part of the survey (sections 2.2 and 2.3) will focus on the introduction of competence-related concepts within performance measurement systems. Indeed, according to [7], each performance control system should include:

- $\quad$ specifications of the expected goals;

- a measurement system concerning the real performance reached (performance indicators);

- a set of performance drivers (potential performance improvement actions).

In the previous paragraph, two complementary types of performance drivers have been identified. They imply the use of two different types of indicators: (i) indicators to measure the available potential of competencies, and (ii) indicators measuring the impact of competencies on processes performance (see Figure 2). The following two sections provide a survey on those two types of indicators.

\subsection{Assessment of competence levels}

In the field of industrial engineering, several models have been developed to provide a systematic and objective evaluation of levels of competencies in a firm. Such information on competence levels is used in industrial engineering methods as raw data needing to be processed by decision support systems. This evaluation can be provided at the level of the individual, collective or global competence of the firm.

Concerning the evaluation of individual competencies, most of the authors choose a similar approach: (1) the results of socio-human researches are used to identify the main models linked to competencies; (2) they provide a formal and qualitative model of the competence; (3) a mathematical and/or quantitative model is proposed to generate a systematic evaluation of competence levels. In a re-engineering context, Harzallah suggests the CRAI model (Competence, Resource, Aspect, Individual), associated with axioms based on set theory [8].

Competencies are characterised by sets of Knowledge, Know-How and Behaviour associated to a context and linked to individual actors. Based on a classical evaluation of the "Knowledge", "Know-How" and "Behaviour" 
Final draft paper published in : Computers in industry, Volume 58, Issue 2, February 2007, Pages 98-117

characteristics, a mathematical aggregation is suggested to provide a quantitative evaluation of competencies. The approach aims at manipulating data bases describing formal competence in order to provide a mapping between required and acquired competence in an enterprise reengineering context. A similar approach of formal evaluation is developed by Jia [9] with an objective of allocation of production actors. Referring to a structural model of competence, Franchini uses a multi-criteria decision tool to aggregate the various factors considered within the competence level [10]. The added value is to provide several evaluations depending on the user's point of view. A fuzzy approach for the evaluation of competencies is also proposed in [1]. An aggregated competence indicator is evaluated by a fuzzy-aggregation of several evaluation criteria. The fuzzy approach is flexible enough to incorporate and combine various criteria; it also has the advantage of allowing an integration of subjective aspects which may be required for the evaluation process. An alternative fuzzy approach with similar objectives has been developed in [12]. Finally, complementary contributions use the results of individual evaluations to provide a better visibility of the potential of competencies available within a firm. They mix the qualitative level of competence of the actors with their quantitative time availability, to provide a global estimation of the available potential on each competence considered [13], [14].

To our best knowledge, few results are yet available concerning the evaluation of collective competencies in the field of industrial engineering. Indeed, socio-human research on collective competence is still recent and the results are not advanced enough to look for industrial engineering-oriented formalisation. However, promising trends have emerged:

One type of models aims at providing decision support system to configure groups of actors. Individual competencies of actors are mapped with competencies requirements. Such contributions can be found in production management [9], [15] or in design (see team building in section 4.3). The configuration of groups of actors aims at a good performance, but the collective competence as such is not evaluated. In the field of project management the profile theory [16] originally proposed by Plekhanova goes one step further. It provides tools to evaluate not only the capability of human resources, but also their mutual compatibility within a group. However, the notion of compatibility remains very simple. Thus, up to now, formal approaches trying to tackle the issue of collective competence refer to a limited view on collective competence: the synergic factors at work in collective efficiency do not seem to be adapted to a formalising process and the collective competence itself is not evaluated.

Finally, numerous articles also show advances concerning competence evaluation at the level of the global competence of the firm. However, such approaches mainly belong to the managerial field, notably with 
Final draft paper published in : Computers in industry, Volume 58, Issue 2, February 2007, Pages 98-117

contributions to value firm intangible assets or to measure their intellectual capital, with application to financial or knowledge management. This field is beyond the scope of the present article. As a matter of fact, at that strategic level, the performance of the firm is usually measured globally, without explicit link to the operational performances of the processes.

\subsection{Causal models: impact of competencies on the performance of processes}

The previous section has only presented research on the assessment of competence levels. Other contributions go further and try to formalise models of the impact of competencies on process performances. The objective is to make explicit the causal relationships between competence levels and operational performances. Competence levels are classically linked to temporal performances, but recent approaches also consider cost or product-quality indicators. Here again, we can distinguish between individual competence, collective competence and global competence of the firm.

In industrial engineering, such research has been first developed with the aim to provide the best allocation of actors to operational processes, depending on their efficacy. In fact, the first results in that field show two strong limitations: (i) as an extension of Taylor's organisational model, only human efficacy is considered, and not really competency levels; (ii) most of these approaches only concentrate on temporal performance, addressing the impact of human efficacy on execution duration [17].

At the very beginning of the 90 's, socio-technical approaches of production systems tried to cope with this limitation by integrating socio-cultural features [18] to take into account more complex models of human factors. El Mhamedi characterises the production operator by several qualitative criteria such as versatility, experience level or control level on working environment [15]. He elaborates an "approximate" model of the performance of a working station (operator/machine), based on the aggregation of criteria characterising both the machine and the operator. This aggregation also integrates a variable to express the impact of the working environment. This work provides an interesting contribution to a better formalisation of the impact of human factors in industrial processes. However, only temporal performances are studied and the robustness of the model would require further development.

In a similar perspective, several approaches have suggested aggregations of the various human factors to be considered by the use of a more elaborated competence model [9], [13], [19]. Qualitative models of individual competence (see section 2.2) are used to formalise the evaluation of competence levels. The causal link between competence and performance remains simple: at the level of a basic activity. It is represented as a dependency 
Final draft paper published in : Computers in industry, Volume 58, Issue 2, February 2007, Pages 98-117

relation between an efficacy factor and the competence levels. Usually, this efficacy factor is used to adapt the nominal performances of the activities, the global performance of processes being built by the aggregation of activity performances. Simulation [9], [20] is the most usual tool to produce such an aggregation, as it will be pointed out in section 4.2. Some articles go even further by formalising the mechanisms of performance evolution: individual learning mechanisms have for instance an impact on medium and long term temporal performances [21], [22].

Concerning the second limitation mentioned above, research from manufacturing-ergonomics stresses the impact of individual levels of competencies on non-temporal performances [23]. In that perspective, Coves presents a model which has neither of the two previous limitations: causality relationships are formalised between individual competencies levels and the operational performances of processes [24]. They are not only applied to delays but also to cost-oriented indicators or product-quality measures. The model itself is very generic, which makes the approach highly flexible. Causality is formalised by dependency relations between performance criteria and performance indicators. The user's expertise is required to define pertinent dimensions of performances, indicators on those dimensions, criteria linked to the indicators and dependency relations between criteria and indicators. However, the overall model is unwieldy to implement in a specific case since it requires a high level of user-expertise. Moreover, the pertinence of the model depends too much on that expertise.

Studies on collective competence are rarer in the field of industrial engineering. A model aiming at representing explicitly the impact of collective competence on the operational performances of processes has been developed in [25]. The authors provide a quantitative model to formalise the impact of cooperation between actors on performances. The quality of cooperation is quantified depending on individual communication criteria and is used to estimate performance modulation coefficients. The correspondence between quality of cooperation and modulation coefficients depends on experimental data from the industrial context. Modulation coefficients then affect the nominal performances of the activities. This formal and quantitative model is used within a simulation environment to provide the aggregation of activity performances. A major interest of that work is to show the great impact of the quality of cooperation on the final performance. However, the model is based on a set of restrictive hypotheses which limit the application and the simulation results depend on experimental data whose reliability is not completely verifiable.

Finally, causal relationships between competence and performance are also studied at the level of the global competencies of the firm. Statistical studies intend to demonstrate a scientific correlation between key 
Final draft paper published in : Computers in industry, Volume 58, Issue 2, February 2007, Pages 98-117

competencies and global productive performances. Some of those contributions analyse the impact of very specific competencies: e.g., Fawcet et al. [26] state that the "delivery capability" of a firm has a strong positive influence on performance. At another level, the authors show that globalisation, information availability and planning sophistication are useful competence inducers for the "delivery capability". The impact of manufacturing flexibility capabilities on performance is also analysed by Zhang et al. [27] who consider customer satisfaction or by Llorens et al. [28] as a critical factor in the process of strategic change.

More than flexibility, Perona and Miragliotta [29] are interested in the impact of complexity management on the supply chain performance. Their model shows that the ability to control complexity within manufacturing and logistic systems can be regarded as a core competence in order to jointly improve efficiency and effectiveness on the wide scale of the supply-chain. In [30], Narasimhan et al. put forward the idea that flexibility depends on "flexibility competence" defined as the ability to convert investments in advanced technologies and strategic source initiatives into manufacturing flexibility. Using a data analysis method, they also show that firms can develop a specific ability to convert their flexibility into higher levels of performance. Their research tends to demonstrate the benefits of competence management on the global performance of a firm.

A general framework for such relationships between performances and manufacturing competencies is elaborated in [31]. The framework shows (i) the relationships among manufacturing capabilities and (ii) the relationships between those capabilities and business performance. Five main manufacturing capabilities are identified: "conformance quality”, "delivery speed”, "delivery dependability, "product flexibility” and "cost management". Such generic model is also to be completed by domain oriented studies such as [32] in pharmaceutical industry or [33] in microelectronics industry.

\subsection{Focus and structure of the survey}

This section provides a survey on research works studying the formal link between competence and performance. One can consider that there is already quite an amount of academic contributions useful for understanding and modelling that link, but in most of the above mentioned studies, competence is only considered as being one dimension of the performance among others. However, it is considered as an important dimension which is still not enough taken into account, often because of a lack of formalisation. Such research is at the frontier between qualitative and quantitative modelling approaches: several contributions clearly pave the way for the development of formal models useful in a perspective of concrete decision support. 
Final draft paper published in : Computers in industry, Volume 58, Issue 2, February 2007, Pages 98-117

As underlined above, the causality relationship between competence and performance can be studied and formally modelled at distinct decision levels. These decision levels will help us make the positioning of the rest of the paper more explicit. Indeed, the overall scientific domain covered by competence oriented approaches applied to industrial processes remains too large for a single state of the art. Table 1 explains the focus chosen in this paper, in the field of industrial engineering methods.

In that table, it is considered that research on competencies focuses on distinct points of view: the structural view is a static point of view concerning mainly identification, structuring and evaluation of competencies. The functional view concerns the mechanisms of competence mobilisation in a working context where the goal is to make the most of available competencies. Finally, the evolution view deals with the evolution processes concerning competencies (notion of competence trajectories and dynamic models).

These three views can be managed at the strategic, tactical or operational levels of decision. In the following sections, we will only concentrate on the tactical level, since most of industrial engineering contributions deal with that level, where concepts have to be formalised for further application in dedicated pieces of software or practical techniques at the operational level. This positioning also excludes the research from strategic managerial sciences, as well as from human and social sciences.

In the following sections, we will develop a survey on the integration of competence models within the information and decision systems of the firm, aiming at answering questions such as: How can these models be integrated in the existing industrial engineering methods? How can the notion of competence be used to implement innovative decision aids for tactical management of the firm? The survey mainly focuses on three fields for which we have found substantial research proposals. The first two deal with two complementary processes within the product life cycle: section 3 provides a survey on competence applied to the management of design processes. Indeed, it is a very active research field aiming at analysing which competencies are required at the various stages of the product and system design. Section 4 will focus on production (operation) management, where a better use of available competencies is nowadays perceived as a major performance driver. Section 5 will be more transversal, regarding design management and production management: the emphasis will be set on the use of competence models for the management of inter-firms relationships.

\section{Competencies in management of design processes}

Products are increasingly more complex. Concurrent Engineering, aiming at decreasing the time to market, is based on the fact that specifications are not completely known at the beginning of the NPD (New Product 
Final draft paper published in : Computers in industry, Volume 58, Issue 2, February 2007, Pages 98-117

Development) projects and are linked to the company strategy by innovation management and core competence management. Solutions are progressively determined, within an iterative process while specifications progressively emerge from the anticipation of the future life cycle of the product. Different kinds of uncertainty (e.g. market trends, changes in norms, new technologies or cognitive conflicts among actors) increase the difficulties of problem solving and decision making during the project, and increase the risks of wrong choices. Concurrent Engineering requires that designers establish assumptions that will be checked later when more knowledge or information have been produced. Multi-disciplinary teams and cross-functional processes are often required to insure the success of NPD. An advantage of team working over individual work should be that a greater number and variety of concepts and knowledge are generated and considered. The collaborative work requires an appropriate communication to share concepts and knowledge, as well as the use of ontologies. One disadvantage of collaboration is related to the possibility of arising conflicts between team members. An appropriate coordination would be necessary to build teams, manage project (team building, project management) and to identify and resolve conflicts. Technical conflicts are normal in design and may be of value when solving complex problems, but interpersonal conflicts have to be avoided. These different aspects of design match various research topics. This section classifies significant contributions related to competence management in the New Product Development processes.

\subsection{Core competencies and design management}

A functional approach to the enterprise management concerns the strategic level that defines global directions according to the changes in the enterprise environment and in its internal capabilities (resources, core competencies...). Research issues are focussed on core and organisational competencies, strategic management of R\&D, innovation management and "competencies destroying" [34], [35]. Some authors are interested in relationships between products and manufacturing systems life cycles and core competence changes: Torkkeli and Tuominen [36]point out that the opportunities to build core competencies should be systematically assessed when selecting technologies and propose a method to clarify the impact of technology selection on core competencies. Especially, high-technological competencies of R\&D involved in innovation projects enhance the design of new functionalities in products and industrial processes and provide the company with a competitive advantage. Numerous works emphasise the linkages between product innovation management (technological changes) and core competencies life cycle [37], [38] . Dawson [39] discusses the uncertainty factor in R\&D organisations and proposes to manage jointly the mix of end products and core competencies, both in the short 
Final draft paper published in : Computers in industry, Volume 58, Issue 2, February 2007, Pages 98-117

term and in the long term. The point is to elaborate methods and tools to select appropriate core competencies that need to be developed, to assure sustainable long-term competitiveness. The link between strategy and NPD organisations design has only been mentioned occasionally in the literature. Large industrial companies have undertaken deep transformations of their organisations to structure, coordinate and facilitate design activities along with knowledge and competence development [40]. Nevertheless, very few studies explicitly link organisational structures and performance. Osterlund [41] deals with effective structuring of NPD processes and considers competence as an essential resource. He proposes an approach to manage competence transfer and development, trying to establish links between effective organisation and core competencies building. This work is based on different models ("resource-box", "decision-box") to structure information flows and to facilitate communication and consequently, virtual team building. The interest of simulation related to the integration of competence in the NPD processes is also discussed.

Nowadays, managers have to define how the design process and the collective activities should be organised and supported to enable designers to reach high performance in design. This issue concerns the integration of competence in NPD processes management, team building and competence allocation, collaborative design and coordination processes.

\subsection{Integration of competence in NPD projects management}

Global directions provided by the strategic level influence the choice of a coherent organisation able to enhance the performance at the tactical level. Major cross-functional processes are defined by describing the expected objects and their intermediate states through the processes. To reach the performance required, coordination has to be properly established to break down each process into a sequence of sub-processes and to integrate each local result. Each sub-process has to be allocated to one actor. Numerous works have focused on models and methodologies to decompose design activities [42], [43] and to perform these activities simultaneously. To reduce the complexity of a large scale project, activities are grouped either on the basis of product structure or on the basis of precedence relationships between activities. These approaches are mainly top-down oriented: competencies are not taken into account since the main focus is set on the temporal organisation of the project. They assume (1) that the individual competencies are available and (2) that collective competencies will emerge from the sum of individual competencies. To tackle this assumption, different research works have proposed an efficient organisation that makes appropriate matches between activity features (task, uncertainty, coordination) and competence features. 
Final draft paper published in : Computers in industry, Volume 58, Issue 2, February 2007, Pages 98-117

Eriksson et al. [44] study projects management competence needs in the customer organisation when designing a large technical system. The authors examine the relationships between customer and supplier to specify the minimum requirement of competencies. They try to find out "who" is most suitable to do "what" according to different initial conditions in the projects studied. Bstieler [45] explores potential effects of environmental uncertainty on the development process, project organisation and on project timeliness with a sample of development projects in two countries, Canada and Australia. In [46], Mc Dermott and O'Connor underline that traditional NPD organisations are not necessarily designed to support uncertainty related to radical innovation projects. The project teams targeting radical innovation encounter a much different set of challenges than those typically faced by NPD teams engaged in incremental innovation, especially human issues both at the designer level and at the project team level. Project activities are subject to considerable uncertainty, which is gradually decreased during project execution. However, project scheduling largely assumes complete information about the process to be planned, which means a static deterministic environment. The fundamental approaches for scheduling under uncertainty are compared in [47]: reactive scheduling, stochastic project scheduling, fuzzy project scheduling, robust (proactive) scheduling and sensitivity analysis. The authors discuss the potentials of these approaches for scheduling under uncertainty projects with deterministic network evolution structure. This literature review shows that no research work has clearly addressed the relationships between competence and uncertainty, along with their simultaneous integration in project management.

\subsection{Team building and competence allocation}

To be successful, NPD teams must be composed of people who work well together. Numerous theories have been developed to characterise roles, personalities or cognitive profiles that facilitate team building. The most famous applied theory was developed in 1981 by R.M. Belbin [48] who defines two role types: functional role (actor function) and role in the team (actor relationships within the team). For this latter type, he identified eight roles required for team performance: Chairman, Shaper, Plant, Monitor-Evaluator, Resource Investigator, Team Worker, Company Worker and Completer-Finisher. An audit form called « Belbin's Self-Perception Inventory » was developed to determine the compatibility between actors and roles. These results are the reference for some works on team building that propose formal models from his theory [49], [50], [51]. Other social theories could become the basis of operational research on collective competence to elaborate decision support systems. For instance, Kichuk and Wiesner [52] identify five important personality factors that could be used as selection variables to determine the "optimal" team composition. A short empirical study allowed the authors to examine 
Final draft paper published in : Computers in industry, Volume 58, Issue 2, February 2007, Pages 98-117

relationships between these personality factors and team performance. Their conclusions need to be confirmed by further experiments, a question being why consider these five factors and only these ones. On the same topic, the importance of member personalities, goals and capacities to control team performance is underlined by [53], [54].

Social theories need deeper investigations but could be used from now on to develop formal models and to design decision support systems with the aim of assisting managers in team building. Indeed, a great deal of attention is focused on team building but only few works propose formal models to improve collective performance and to control risks of failure. Some relevant papers have been selected as follows.

Chen and Lin [55] develop a mathematical model and a five-step approach to support team building. The authors define quantitative levels of competence based on three characteristics (functional competence, capacity to work in team and personality profile). They use the Analytic Hierarchy Process method to compare different designers according to their competencies and to select the most appropriate members for the team. Fuzzy logic is used in [49] to model the interactions between team members, based on Belbin's framework. Along the same lines, a team building approach is proposed in the field of collaborative design by [51]. The authors use team roles as defined above by Belbin and introduce an indicator related to the designer ability to cooperate. Their assignment model is expressed as an integer-linear program that maximises the sum of the evaluation of the selected designers. The previous works have some limits and assumptions that have to be pointed out: they do not predict the planned performance of the team; they do not sufficiently evaluate the risk of project failure; and they only suggest static approaches to team organisation. Further works could study the links between team building and process decomposition in the team.

Acuna and Juristo [56] propose a qualitative model and a procedure to assign people to perform roles in software development projects, depending on their capabilities and the capabilities required by the role. Their capabilities-oriented process model includes traditional elements (activities, products, techniques, people and roles) and an original element: capability in order to add behavioural competencies to the process model. According to the authors, their method improves software development performance. Tsai et al. [57] state that team building for a software development project is "an important issue for reducing project cost, duration, and risk". They propose a computational method to solve the resource selection problem, based on two steps: firstly, they build a critical resource diagram to show the interrelationships among human resources and tasks. Secondly, they implement a Taguchi parameter design approach to select appropriate human resources. In their works, they consider human resources as controllable and they show that under these assumptions, their approach is efficient 
Final draft paper published in : Computers in industry, Volume 58, Issue 2, February 2007, Pages 98-117

and effective for human resource selection. In the same field, De Korvin et al. [58] develop a model and an algorithm for allocating human resources to a team for a multi-phase project subject to meeting quality limits. The authors identify the necessary resources, namely skills to perform the various activities and costs involved for the salaries of the personnel who possess these skills. Fuzzy compatibility indicators are constructed to measure the acceptable quality levels of the team building process. Trade-offs in membership are made due to budget considerations. According to the authors, their method is applicable to cross-functional team definition and improves team performance.

A framework and an intranet solution for an electronic market of human competencies is proposed in [59], in order to facilitate the team building process in the context of multi-site and large companies. An information phase should allow buyer and supplier pairs to meet. The point is to properly represent task requirements and competencies to enable high effectiveness of the search for potential candidates and of the matching process. They propose a classification divided into four categories: knowledge, enabling technologies (tools to act in the task), fields of experience (environment) and personal traits ("to ensure a proper integration and a balanced team"). For each dimension, two values are required (min and max). Even if the approach seems to be interesting, the authors do not explain how the aggregation is performed to obtain a proximity ratio, and assertive hypotheses are formulated without being made explicit: the sum of individual competencies does not enable one to obtain a collective competency.

\subsection{Integration of competence in collaborative works and coordination processes}

In the field of design, another important issue closely linked to competence management concerns collaborative processes and tools. Even if the authors working on the collaborative design are not interested explicitly in modelling competence, their results are useful to structure collective competence and to improve the performance of design processes. According to Torkkeli and Tuominen [36],"the application of the technological capabilities of R\&D in specific innovation projects to produce new functionalities in products and processes depends on complex coordination processes". Some relevant papers are presented below.

NPD processes in manufacturing organisations are distributed and knowledge-intensive [60]. To tackle this challenge, Madhusudan presents an Agent-based Process Coordination (APC) framework for distributed design process management [61]. The framework uses a centralised decision-making and task sharing approach to support design activities. This study illustrates the interest of deploying agent-based workflow technologies to: (a) enable incremental and large-scale process and product knowledge acquisition and management, (b) facilitate 
Final draft paper published in : Computers in industry, Volume 58, Issue 2, February 2007, Pages 98-117

design process knowledge reuse in different contexts, and (c) support distributed dynamic process management. An agent model based on the concepts of role, process and information is proposed in [62] to support the collective decision in collaborative product design. The points are to find mechanisms to support information sharing and exchange, to organise the members of actors-network according to their knowledge/competence and to plan the general decision process. The development of design supports requires integrated product and process models to describe and organise activities, information and decisions involved in design. In [63], Lee et al. propose an entity-based integrated model that uses product and process entities to represent respectively design information and design activities. Organisational relationships organise entities into hierarchies, interaction relationships characterise the nature of entity interactions and sequence relationships identify the sequences in which process entities are initiated during the design process. Companies do not possess all the knowledge they need but instead rely on other organisations: this point results in the need of distant product development, which in turn requires information and knowledge in the place, time and format required. In response to this need, a knowledge-driven collaborative product development system architecture is developed in [64], in order to facilitate the provision of knowledge involved in product development.

Even if the links between knowledge management and performance optimisation are beyond the scope of this paper, it seems obvious that such collaborative computer tools facilitate competence mobilisation and development. Moreover, very few approaches aim at integrating product, process and competence models. However, it would be useful to develop integrated computer tools that could automatically identify competence. Numerous research works focus on collaborative works or processes coordination and produce formal models (mathematical or simulation models). These models could be enriched to be even more realistic or relevant by taking into account competence more explicitly.

\subsection{Competence development in design process management}

When organisational structures and collaborative supports have been defined, the design activities are performed (at the operational level), either by an individual actor or by a collective actor (a team, a work group...). Objects manipulated by designers play a crucial role at this level [65], [66]. They enable designers to co-elaborate shared representations, to make mutual interactions easier and then to develop collective competence. Design organisation is based on the interactions of multiple actors. Artefacts and representations of the design process have a key function in the organisation of this activity. Nowadays, an abundant literature deals with collaborative design activities and more specifically with collective learning processes that are closely 
Final draft paper published in : Computers in industry, Volume 58, Issue 2, February 2007, Pages 98-117

related to product dynamics [67]. Organisational learning is believed to be important for competitive performance of companies. Several works examine how organisations learn from experience of the introduction of new product and propose recommendations to help companies to build a learning organisation in R\&D [68], [69]. Moreover, companies that neglect post-project reviews as a way of inter-project learning waste invaluable potential for competence building.

\subsection{Conclusion on management of design processes}

In the field of design, two research approaches can be noticed: either competence is considered as a valuable asset and needs to be properly managed, or this dimension is not directly addressed but the concerned topics involve changes in human competencies. The latter is the most widespread, even if, today, the trend in Engineering Design has more to do with explicitly studying the impact of managerial and organisational decisions on competence. The links between performance evaluation of design process and competence management have not been explicitly addressed in the literature. Competence is considered as an input data for project management or team building but it is not integrated as a joint result. The performance evaluation has been focusing on the main objects, related to the product and the manufacturing system (in Concurrent Engineering) but competence development process has seldom been evaluated with explicit criteria related to knowledge or competence expansion.

\section{Competencies in production management}

Production management can be considered as the synchronisation between informational and material flows, taking into account different types of constraints including the availability of resources like machines but also operators. In the following, we have been mainly interested in how the human resources are considered and modelled for solving this synchronisation problem. Depending on the objectives of the process, two main areas have been distinguished: scheduling of a workforce, in order to generate the planning which will organise production, and simulating the workshop, including its human resources, in order to assess its performance.

\subsection{Scheduling a workforce}

Scheduling is not a new but still active application field of operations research in manufacturing.

Traditionally, the question has been to allocate tasks to resources through time, these resources being most of the time machines. An interesting exception is nevertheless the Hungarian method (described for instance in [70]) aiming at providing an optimal solution to a problem where tasks were to be allocated to people having different 
Final draft paper published in : Computers in industry, Volume 58, Issue 2, February 2007, Pages 98-117

speeds for performing these tasks. In spite of this example and other similar ones, the explicit consideration of workers in the manufacturing activities has mainly come from industrial scheduling packages that became available in the 80 's on personal computers. In this type of software, human resource was considered as a subproblem of multi-resource scheduling: a task was requiring a machine according to a part routing, but also eventually a worker. In most scheduling packages (and still in modern ones), an ordered list of operators was associated to a machine. Once the scheduler has positioned a task in time, the software will look for the first available worker in the list. Implicitly, the ranking in the list conditions the skill of the person on the machine.

On the other hand, rostering or staff scheduling techniques were another point of interest of operations research. The problem, in that case, is to define a work plan for a set of persons, within a given working period. Staff scheduling and rostering techniques have for instance been applied to transportation systems (e.g. airlines or railways), healthcare systems, emergency services (police, ambulance, fire brigade), call centres, service organisations (e.g. restaurants, hotels or retail stores) and occasionally in manufacturing [71]. In most of these cases, the problem consists in dimensioning a workforce at lower cost in order to answer a demand. No mention of skills or competencies has been made since, usually, tasks can be performed by all the workers (see the typical cases about mail processing in [73] and [74] or nurse rostering in [75]). In [76], Lee notices for instance that the existing literature on employees scheduling problems does not take into consideration the quality of service provided by persons characterised by distinct skills and work speeds. It seems nevertheless that reality is a somewhat more paradoxical, since in many works, skills are emphasised as being an important issue of staff scheduling... but are not considered in the suggested models. It is, for instance, typical to see that some papers define staff scheduling as finding weekly schedules for each employee in a given skill category [72], or state that task assignment should be made according to individual skill strength [77], [76] but do not include this concept in their framework. Similarly, a survey on the nurse rostering problem [78] considers as a hard constraint the respect of the nurse skill level and category, whereas none of the papers referenced in this survey seems to fully consider this constraint. Nevertheless, different categories of workers are sometimes considered in simple cases, like in mail processing in [79], where clerks are considered as linked to machines and are scheduled first, while the requirements for mail handlers are established as a second step through simulation. In other works, skills are expressed through the definition of a hierarchy for performing a task [80], [81], which is quite similar to the method used by the industrial scheduling packages described above. In that case, it can be possible to "downgrade" a person of a given skill level by allocating him to a lower level task instead of keeping him underloaded [81]. This technique introduces new degrees of freedom but can lead to dissatisfaction problems. In [82], 
Final draft paper published in : Computers in industry, Volume 58, Issue 2, February 2007, Pages 98-117

the use of a genetic algorithm for scheduling a staff of mixed skills is suggested. Once again, it is underlined in the article that traditional research usually considers only simplified models, with staff having homogeneous skills. Nevertheless, only a very simple example is detailed in this paper for mixed skills management: two types of jobs are considered with three skills, one allowing to perform the first job, another the second and the third one both of them.

In many works, competence is only considered as being related to performance in terms of speed to perform a task, which is close to the scope of the Hungarian method. In [83], the number of workers required to perform a set of tasks is for instance assessed first, then an allocation of tasks to persons is made in order to optimise performance. The influence on the customer delay of workers having different capabilities in terms of speed is also addressed in [76], in which it is also noticed that the existing literature on employee scheduling problems does not take into account the quality of service provided by persons of various skills. Indeed, workers are often considered in these studies as all able to perform a task (with different performance), whereas other works consider strict skill categories (i.e. the worker needs to possess a skill in order to be authorised to perform a task) within which workers are considered as similar.

In the manufacturing area, two studies emphasise the interest of defining skills or competencies at the planning or scheduling level [84], [14]. The framework of annualised hours is considered in [14]. Here the authors have used a questionnaire sent to companies to determine to which entity the operator should be linked (parts, operation or resource). On the base of the answers, competencies are defined as mainly related to operations or to resources, leading to the definition of skills such as "controller", "setter" and "operator", the last two being applied to various machines. A method is then suggested to translate a production plan into a "competence requirement planning". Constraint propagation is finally used in order to allocate multi-competent workers in the context of annualised hours.

In [84], the objective is also to manage critical skills through a "Skill Requirement Planning". Skills are linked to a type of operations (e.g. manufacturing, transport, set-up quality control, etc.) and are considered once a schedule based on the allocation of operations to machines has been performed, using a "classical" scheduling tool. The number of operators required per period is calculated, together with a "skill workload" per period. The result is an assignment of the operators to the operations or resources. 
Final draft paper published in : Computers in industry, Volume 58, Issue 2, February 2007, Pages 98-117

At a higher level, ERP (Enterprise Resource Planning) systems are software tools which are supposed to provide a comprehensive solution for all aspects regarding the management of a company. The largest systems include both human resource (HR) management and production planning modules. In most of them, the human resource management focuses on employee management, payroll, training, recruitment and time management but only the most comprehensive include skill management. For instance, qualification profiles can be associated to persons in the HR module of SAP R/3 (leader of the ERP systems), allowing for instance to compare a person to a position (SAP, 2003). Within the production planning module, a work centre can be defined as a machine or a group of machines but also a person or a group of persons, and therefore be linked with the persons listed in the HR module. In a routing, a qualification can be requested to allow an operator to perform an operation.

\subsection{Competence in simulation systems}

Simulation of manufacturing systems has many common points with scheduling (because it considers the same entities) but it differs in terms of objectives (mainly, assessing the performance of a workshop) which leads to a clear distinction between schedulers and simulation tools. Especially, simulation tools do not have all the facilities for planning the production over time by including follow-up modules and do not easily allow an incremental planning (i.e. a new schedule is built periodically on the basis of the past one, updated by the followup information). On the other hand, simulation tools must support the assessment of new layouts or control of policies and, therefore, are usually more open to changes in the input data than scheduling tools. They also include facilities aiming at simulating disturbances in order to assess not only the ideal workshop behaviour but also a more realistic one, including disturbances.

Building a realistic simulation model necessarily requires taking into account the critical resources of the workshop. Like in the scheduling area, recent studies have emphasised the interest of better consideration of the human resource in the scheduling models. Two white papers ${ }^{2}$ from the HUCENS (Human Centered Simulation) working group of the Sim-Serv project provide for instance a recent summary on the subject, concerning both the research literature and the commercial simulation tools. The following statements are largely extracted from these reference white papers.

Since simulation is mainly oriented on performance assessment, the research literature on the subject is also oriented on human performance in production systems, which depends on technical concerns but also on psycho-

2 available at http://www.sim-serv.com 
Final draft paper published in : Computers in industry, Volume 58, Issue 2, February 2007, Pages 98-117

physical attitude in carrying out operations, on physical and mental stress, on learning processes and on human skills [20], [86], [87]. Thus, personnel-oriented simulation requires additional information linked to personnel qualification, learning and unlearning effects, etc, which are seldom present in material-oriented simulation tools. In spite of this, the literature on the qualification issues is very poor, human aspects focusing often on ergonomic aspects (linked to the position or efforts of the operator at work) or performance (for instance through models of tiredness).

Simulation tools are mainly oriented on the resolution of industrial problems and, as a consequence, the concept of skill is better taken into account in these products than in the research literature. In commercial simulation tools, skills and qualifications are dealt with very much like scheduling tools, even if more flexibility is allowed:

- In Arena ${ }^{\mathrm{TM}}{ }^{3}$, human resources can be allocated to tasks according to a given set of pre-defined rules, which can also be customised, including skills considered as the possibility to perform a given task.

- In Dosimis $3^{\mathrm{T} \mathrm{M}^{4}}$, the number of workers and their qualification can be defined for each task separately. A task may be assigned to a worker according to three criteria: qualification, idle time and distance.

- In eM-Plant ${ }^{\mathrm{TM}}{ }^{5}$, various services can be defined for processing a part. These services can be treated as human resources skills and it is possible to define pools of workers of the same skill. The skill may influence the efficiency of the worker.

- In Witness ${ }^{\mathrm{TM}}{ }^{6}$, human resources are specific entities which can be called by other simulation objects (e.g. machines, conveyors, vehicles) in order to perform an operation (e.g. set-up, cleaning, repair, drive a vehicle, etc.). An operator can have simple or multiple competencies. He can work on a workstation and be competent for setting-up machines and repairing simple failures (complex ones being tackled by specialists).

In all these products, more accurate models of qualification or skills can be integrated in the standard functionalities thanks to the openness of the products, but the effort required may be substantial.

\footnotetext{
${ }^{3} \mathrm{http} ;: / /$ www.arenasimulation.com

${ }^{4} \mathrm{http}: / /$ www.sdz.de/dosimis/tutorial/dosimis_3_tutorial_english.pdf

${ }^{5} \mathrm{http}: / /$ www.tecnomatix.com

${ }^{6} \mathrm{http}: / /$ www.lanner.com
} 
Final draft paper published in : Computers in industry, Volume 58, Issue 2, February 2007, Pages 98-117

Therefore, the standard integration of the workforce skill and competence in simulation tools is very similar to the one for scheduling tools, the main difference being that it is nevertheless possible to adapt these tools to more demanding requirements.

\subsection{Conclusion on production management}

As a summary to this section, it is clear that two types of problems are usually considered in the literature on workforce planning and scheduling:

- The major part of this literature is made of articles related to staff scheduling or rostering, where competencies (usually considered as "skills") are at best considered as a hierarchy of categories allowing to allocate people to teams or operations. In this part of the literature, simple skill models are marginally used for building teams or for allocating persons to tasks but there is never any link with the technical data required for manufacturing scheduling (bills of materials, routings, machines etc.).

- On the other hand, the manufacturing scheduling area has historically focused on the allocation of tasks to machines. In coherence with the MRP II (Manufacturing Resource Planning) method, the critical resources are still often considered as machines, the workforce being usually considered in a second step as additional resources, skills being managed again through very simple models. Even in the rare case where human resource is the central point of interest of a planning or scheduling method, only very basic models of competence are used which are far from expressing the complexity of the operational aspects of competence management.

The state of play in simulation is somehow different since facilities are often provided in simulation tools in order to allow the user to describe with the required accuracy the criteria which may lead to allocate a task to one operator rather than another. Nevertheless, no generic framework is suggested, and there is a huge gap between a very simple off-the-shelf description of basic skills/competencies and the possibility to define its own framework, requiring an important development effort.

\section{Competencies for the management of distributed organisations and supply chains}

It is a very topical issue to underline the important industrial and research needs linked to the deployment of extended and/or distributed organisations. The distribution of productive activities among a set of independent but collaborative partners requires new coordination mechanisms characterised by real flexibility in the composition of the production chain, due to potential changes of the partners. This raises specific challenges 
Final draft paper published in : Computers in industry, Volume 58, Issue 2, February 2007, Pages 98-117

linked to competence-oriented management of processes. There is therefore a strong tendency of the firms to concentrate on their core competencies and, consequently, there is a great coordination need among partners. In that context, complementariness of competencies becomes a key point of the overall system performance. In most cases of creation of networked organisations, several companies try to cooperate in order to make a new "collective corpus of competencies" operational [88], [89]. This link is clearly stressed in recent definitions of virtual organisations including: "a temporary alliance between a number of core competence based firms/individuals, formed to take advantage of market opportunities" in [89] or "a series of co-operating nodes of core competence which form a supply chain in order to address a specific opportunity in the market place" in[90]. Thus, taking advantage of the cooperation, distributed organisations provide higher innovation capabilities, as well as opportunities of savings on transactions costs [91], which can even be applied to competencies transfers [92].

The dynamics of competencies development and competencies mobilisation depend on the characteristics of the distributed enterprise considered. Referring to a stability criterion (linked to the life-duration of the network) this survey is structured according to two generic categories of distributed organisations. These categories ${ }^{7}$ will help to identify different types of competence-oriented control mechanisms, depending on stability and temporality.

The first category refers to short-term distributed organisations with low level of stability (including for instance Virtual Organisations or “On-demand” Supply Chains). That field of research has been very productive along recent years and a competence focus is often considered in the management of such organisations. Here, competence models are mainly used to look for the best productive pattern of the distributed business processes. The selection of partners within virtual organisations depending on the requirements appears as a key performance driver. Most of the approaches are oriented on decision aid tools and methods. Section 5.1 provides a survey of the use of competence models aiming at the configuration of short-term distributed organisations.

The second category refers to long term inter-enterprises co-operations, with a rather high level of stability. Such distributed organisations are usual for SME and refer for instance to SME-Clusters in Great Britain, SMEDistricts in Italy or "Systèmes Productifs Locaux" (SPL) in France. There is a large amount of research work on

\footnotetext{
${ }^{7}$ There is no real frontier between these two generic categories and all intermediary situations are possible. However, that distinction helps to better understand competence-oriented mechanisms. Long-term and short-term competence dynamics are not in opposition but complementary.
} 
Final draft paper published in : Computers in industry, Volume 58, Issue 2, February 2007, Pages 98-117

such organisational structures and Peillon [93] synthesises the main characteristics of those networks as far as competence development is concerned:

- The partnerships between firms are durable and motivated by a shared strategy on competence development, even if each partner keeps its own goals.

- The network consists in relations characterised by interdependencies and by shared investments, for which the notion of equity between partners is a major issue for a good coordination of collaborative actions.

Section 5.2 will put the focus on the mechanisms of competence evolution for those long-term and stable inter-firm co-operations. We will underline three complementary orientations: (i) the link with life cycle management for networked organisations; (ii) decision support for the constitution of long-term clusters; and (iii) management of the collective competence within those distributed processes

\subsection{Competence based configuration of short-term distributed processes}

Among the various challenges faced by virtual organisations, the selection of partners and the configuration of efficient business processes appear as major drivers of performance improvement [94]. Indeed, a poor partner selection is often a key failure factor resulting in a gap between competence requirements and real qualification of the partners [95], [96]. Furthermore, the agile and fast configuration of virtual organisations leaves very little time for the process of evaluation and selection [97], which puts forth a real need for decision support to ensure the consistence of decision processes. This section will thus synthesise advances in decision support systems integrating the competence dimension.

The industrial need for decision support tools is confirmed by several authors. Tuma [91] considers virtual organisations as a combination of core competencies of single partners, which implies, for each partner, a mechanism of concentration on its strategic competencies. The author underlines the crucial need of Decision Support Systems (DSS) to address specific issues of production networks linked to competencies: the allocation of adequate project partners to sub-tasks, the redistribution of project earnings and the harmonisation of distributed production processes. In [98], the authors emphasise the collaborative decision process leading to agreements between partners to solve the problem of combining their different competencies. A framework is proposed, based on a classification of the roles of partners and on the identification of key firm-competencies, in order to structure collaborative relationships. With the same perspective, Pedersen and Van den Berg put forth the need of competence modelling as a basis for decision aids [97]. A French project [99] suggests a structuring of the various needs of decision-making tools to support the coordination and development of competencies 
Final draft paper published in : Computers in industry, Volume 58, Issue 2, February 2007, Pages 98-117

within networks of SMEs. These needs are defined in reference to three main decision processes: performance improvement for the distributed processes, life cycle management for networks of SMEs and internal competencies development. Contributions using a competence approach can also be found in projects focusing on distributed enterprises like GLOBEMEN [100], VOSTER [101] or COMET [102].

The Multi Agents Systems (MAS) are often used to build decision support systems for partner selection. Several authors have underlined the relevance of MAS approach to model virtual organisations, due to the structural correspondence between the distributed model and the distributed organisation itself [103], [104], [91]. MAS approaches are also very appropriate to define competence oriented models. In [105], the core competencies characterising companies are used as decision-making criteria to assign tasks to actors. The multiagent model proposed aims at solving administrative operations for a manufacturing network. Administrative tasks like "Identifying firms suitable to handle a specific mission" are executed by a group of Intelligent Agents associated with a genetic algorithm scheme. In that case, the agents represent administrative actors but they do not directly represent the companies in the network. In [106], the authors define the partners of a nonhierarchical production network as competence-cells. Their contribution focuses on automated negotiation between partners in order to build a productive network able to answer the customer requests. The approach proposes a software agent able to carry out an automated negotiation to assist the human decision-maker and accelerate the harmonisation of individual interests. The feasibility of the approach has been demonstrated but not its complete applicability to real cases. In relation with the Globemen project and the Virtual Enterprise Reference Architecture and Methodology (VERAM), Petersen [104] develops a multi-agent architecture to cope with virtual enterprise formation process (evaluation and selection of partners). In that case, agents are used both to provide models of the potential partners and to provide models of the negotiation processes between partners. Activities within the virtual enterprise require roles and roles require skills and competencies from the agents (candidate companies). A generic model of the process of partner selection is proposed, where the requirements for a virtual organisation are compared to skills and availability of the partners. A multi-criteria utility function is calculated to provide a ranking of the partners. The approach presents the advantage of having been tested on five case studies, with results showing a clear added value for decision-makers, especially in a context of high number of potential combinations.

However, MAS is not the only way to deal with this decisional process and to represent competence-oriented models. Different types of analytical methods have also been applied to solve that problem. Hammami et al. [107] suggest a method to allocate customers orders within a network of firms based on four mains concepts: 
Final draft paper published in : Computers in industry, Volume 58, Issue 2, February 2007, Pages 98-117

actor, activity, resource and competence. The requirements of competencies are specified as characteristics of the activities required for a product. They are mapped with available competence lists for each candidate company. Competencies are defined as "abilities of an actor (a firm) to achieve an activity using a resource" and are characterised by the activity they can contribute to, by the resource(s) they require, by a level of expertise and also by a learning mechanism ${ }^{8}$ considered to change the level of expertise. The lists of firms competencies are identified referring to a generic and standardised competency frame used in France ${ }^{9}$. The "Multi-Objective Programming" operations research method is used to provide a mathematical model of the decision problem, with three final performances observed: Cost, Quality and Delivery time. The method generates evaluated patterns of firm networks matching the requirements of an order.

Ant Colony Optimisation, completed by an Analytic Hierarchy Process approach are also used to solve similar problems [108]. Potential partners for a virtual organisation are modelled as "competence-cells". Competencies are not directly modelled, but in order to fit a customer demand, each cell makes a competenceoffer characterised by the activity to be performed within the production network, the working plan for that activity, the performance expected (delivery time, probability of delivery, price), a potential of flexibility (possibility of production capacity adaptation) and, finally, social attributes of the competence-cells. Thus, the authors combine an external model in which the competence is mainly characterised by its quantitative result in terms of performance with an internal model in which the competence is characterised by qualitative attributes such as its potential of flexibility or some social features. For each demand, these characteristics are considered when selecting the partners for the production network. A specific added value of the approach is to consider social factors during the decision process. However, the article is not explicit on which features are really represented.

Szegheo and Petersen [109] present a computer-aided approach for the selection of partners based on competence descriptions. However, the mathematical representation of the decision-making process is not defined. Complementary approaches focus on the link between the notion of role and the notion of competence. In a context of virtual supply chain, Manthou et al. [98] underline the notion of role in the process of partners

\footnotetext{
${ }^{8}$ That attribute is used to take into account learning policies of each partner.

${ }^{9}$ The French national standard ROME, « Répertoire Opérationel des Métiers et de 1'Emploi »
} 
Final draft paper published in : Computers in industry, Volume 58, Issue 2, February 2007, Pages 98-117

selection. In that perspective, Zaidat et al. [110] characterise an "organisational role" by the competencies or macro-competencies ${ }^{10}$ required to fulfil a specific mission.

All the contributions referred to above are based on a selection of partners depending on their "functional competencies", i.e. competencies to carry out a phase of the product life cycle. Another type of approach for the configuration of virtual organisations suggests taking into account an evaluation of the "collaboration competencies" of the partners. In this case, the question is not to allocate activities to partners, but to evaluate what Pedersen and Van den Berg call the "alliance competence" [97]: the competence in developing interaction and integration with other partners to achieve common objectives. In that perspective, when considering the mutual suitability of the partner capabilities, some authors propose to formalise compatibility factors between candidate companies [111]. The approach takes into account knowledge and skills of the proposed resources and evaluates the overall capability and compatibility of partners with reference to the requirements. This contribution suggests an interesting use of the "profile theory" developed in the project management literature to manage knowledge and skills profiles of partners. However, the notion of compatibility remains vague and insufficient to express all the dimensions of the suitability between partner competencies: a deeper insight on this issue remains necessary. If the ability to cooperate has been recognised as a key performance factor for virtual organisations, very few methods seem to provide a solution to evaluate such factors.

\subsection{Dynamics of competencies within stable distributed organisations}

Dynamics of competencies within a stable distributed organisation can be linked to the management of the organisation life cycle. The global objective is to be able to manage consistent trajectories of the organisation over long time periods to enhance long-term performances. In the domain of industrial engineering, most of the life-cycle models of virtual organisations ${ }^{11}$ focus on short-term life-cycle, from the "identification of partners" step to the "dissolution of the organisation" step when the mission has come to an end. However, focusing on long-term stable clusters, Burlat et al. [112] suggest an interesting model of life-cycle applied to firm networks, which integrates the competence at two levels. On the first level, competencies are used to generate a typology of networks depending on two criteria: similar competencies and complementary activities. On the second level,

10 Macro-competencies are defined as the combination of (individual and collective) competencies, which allows a macroscopic specification of the internal potential of competence a firm has, so that it can perform all the necessary activities for its production of goods and services

\footnotetext{
${ }^{11}$ See [114] for a survey on that issue.
} 
Final draft paper published in : Computers in industry, Volume 58, Issue 2, February 2007, Pages 98-117

the life cycle considers distinct degrees of maturity for the network. These degrees can rank from a simple regrouping reaction when the environment has been disrupted (for example, loss of customers), to a collective innovation (for instance, joint creation of a novel product). The elaboration of a collective competence represents one of the maturity levels on the way to collective innovation.

Within virtual organisation life cycle management, a key issue is the identification of long term stable clusters, which can be later used as sets of potential partners for shorter duration virtual organisations. Models of competence can be useful for the elaboration of such clusters. A specific algorithm to generate clusters of partners based on the two criteria "similarity of competencies" and "complementariness of activities" is proposed in [113]. Four generic coordination modes between firms are defined (Fusion/acquisition, proactive network, defensive network and coordination by the market) and, for a set of potential partners, the relevance of these modes is measured depending on the two previous criteria. Here again, the sets of competencies for each partner are identified referring to a standardised competency frame (ROME), and each competence is merely characterised by a quantified level of expertise. This standardisation makes the competency sets comparable and thus allows to define a similarity between them. The model is formalised using the subset theory and the similarity measure is a generalised Hamming distance between two competency sets. Similarity of competencies is completed by complementariness of activities in order to elaborate a complete clustering approach. The overall methodology developed by the authors aims at helping the managers to define a strategy of interorganisational cooperation.

As pointed out before, such long-term clusters provide good environments for collaborative competence development to improve the overall performance of the virtual organisation. From that angle, other approaches define a managerial model for the competence developments in the form of clusters [89]. The approach is based again on the concept of core competencies and identifies their development over time as the primary strategic objective of a firm within a virtual organisation. Each partner is characterised by (i) a well defined, focused competence and (ii) a mode of delivery of the core competencies to the market, which allows operations to take place rapidly and on a temporary basis. The added-value of the model is on the specification of five steps in competence development for such clusters, but the approach remains at the managerial level and the authors do not propose any real formalisation of competence dynamics. Boucher and Lebureau [92] go beyond managerial models and propose the formalisation of a decision-making process to elaborate a plan of action for competence development within SME clusters. The authors use a multi-criteria decisional method to select the most consistent actions of competence development to fulfil the distinct objectives of all partners. Firm competencies 
Final draft paper published in : Computers in industry, Volume 58, Issue 2, February 2007, Pages 98-117

are considered as dependent on three main factors: the methods deployed in the firms, the skills of employees and the technological context. This leads to a structural model where the competence is formalised as the interaction between three components: actors, material resources and professional situations. These three components imply three types of basic actions to constitute plans of action for competence development: actions on the methods, on the skills or on technological resources. The elaboration of adequate plans of action uses five decisional criteria including evaluation of value creation, cost generation and equity between partners. However, the approach is limited to competence increase for individual firms within a network and it does not cover the increase of collective competence of the network itself.

Finally, the dynamics of competencies within distributed organisations is often linked with the development of a collective competence. This issue is at the frontier of the scope of this paper, since the question does not directly concern the integration of competence concepts in the information system but, on the contrary, the use of the information system as a support for collective competence. In [115], Erbe underlines that network task processing needs collective competencies and points out the requirement for distributed learning process mechanisms. Networked enterprises can be achieved through a cooperative learning process where distributed tasks have to be enhanced and not restricted to well-defined sets of core competencies. His contribution intends to structure organisational learning through three complementary levels: learning within each individual enterprise, learning within a stable network of enterprises and learning within the dynamic business process of a virtual enterprise. Most of the contributions aimed at supporting the emergence of a distributed collective competence are oriented on the improvement of the collaborative working environment. In [116], Nullmeier discusses how ICT can promote or hamper networking and development of a collective competence. Gerber $e t$ al. [117] have developed a method to control the quality related information flow between Units of Competence that are temporarily combined in a production network. Complementary approaches like [118] put the focus on the mechanisms of knowledge exchanges within groups of actors merging within distributed organisations. However, other works stress that besides the implementation of technology, the success of firm networks is also conditioned by the capability of management and workforce for cooperative work [119]. In that perspective, Bowersox et al. [120] specify requirements on the competencies to be developed in order to enhance collaboration and performance within distributed supply chains. 
Final draft paper published in : Computers in industry, Volume 58, Issue 2, February 2007, Pages 98-117

\subsection{Conclusions on the section}

With regards to the two previous fields studied (design management and production management), the management of distributed organisations and processes implies a more global view of the competence, focusing on coordination mechanisms of global actors representing organisations as a whole. Depending on the life-cycle duration of the distributed organisation considered, we have identified two main research orientations on the link between competence and process performance: on one side, the configuration of distributed processes based on competence mapping; on the other side, the management of competence dynamics to enhance long term performance of stable networks. It is interesting to point out that these two orientations tend to correspond to the two generic types of competence based-actions aimed at enhancing process performance that we identified in section 2 (Figure 2): better use of competencies within the processes versus increase of competence levels.

However, a serious limitation lies in the frontier which appears between these two types of action means. So far, configuration of short-term virtual organisations has been based on a static view of competencies. This could certainly be improved with more dynamic and anticipative models of competence. This perspective will be developed in section 6 .

Another crucial issue for virtual organisations is the clear need of organisational competencies qualification. As underlined in [104], candidate companies for virtual organisation tend more and more to coordinate through e-business computerised environments (e.g. AGORAs). In such context, there is a crucial need for the potential partners to be able to rely on a systematic way of qualifying the competencies and services offered by each company. Methods like People CMM (Capability Maturity Model) are certainly a good starting point. However, up to now there has been no convergence concerning the evaluation of firm competencies: evaluation can be binary as in [104] - a firm has or does not have a given competence - or with several levels as in [107]. But overall, the way to evaluate competence is generally not specified at all. So, the question of the validity of the data in use remains a problem. Furthermore, some approaches mix competence evaluation and performance evaluation while both should be distinguished. For instance, in [108] the level of competence is directly characterised by performance indicators on cost and delivery time. Such an approach leads to a dangerous bias since the performance resulting from the activation of a given competence depends really on the context. Typically, in changing contexts like virtual organisations, there is a need to have a clear separation between competence evaluation and the performance generated. Indeed, the performance is not easily predictable, even when the competencies have been assessed. 
Final draft paper published in : Computers in industry, Volume 58, Issue 2, February 2007, Pages 98-117

\section{Trends for future research}

Table 2 proposes a grid positioning most of the contributions analysed in the paper. The first dimension of the table differentiates the granularity level used to model the competence; the second dimension identifies both the level of formalisation of the models in use and the type of application.

Of course, this table has should be read keeping in mind the limits specified for this survey: focus on the industrial engineering field and on the tactical level of management. This explains the large number of formal models identified, while many qualitative models and methods are available in other research areas.

As first conclusions, we can point out that there is increasing research work dealing with the notion of competence. At different levels of management as well as at different levels of modelling, competence has been identified as a performance driver (and not a performance indicator). It has been formally demonstrated that the selection of competencies has measurable impacts on classical performance indicators such as cost, delivery times or quality of product. Taking into account the dynamics of competencies, this leads us also to consider that increases or losses of competencies over time should have measurable impacts on enterprise performances.

The focus on a research field directly linked to industrial applications has led to considering various case studies. However, after a close analysis of these applications, we can clearly point out that the operational use of competence models is still in an emerging phase. Table 2 underlines the lack of tools allowing a professional use of such concepts ${ }^{12}$. There is still an important need of knowledge and know-how transfer from academic studies to industrial applications.

Indeed, even if the basic competence-related concepts seem stabilised, they are not operational yet. There is neither consensus nor synthetic view on the causal relationships linking performance and competence. No generic and widely accepted model is available to connect competence concepts with the other "objects" of performance models (e.g. processes, tasks, roles...). Because of this lack of consensus or standardisation, the notion of competence remains rather poorly formulated in most of the papers. It is typically the case in the field of virtual organisations, where decision-making approaches do not use structural models of the competence as those identified in section 2, for instance those proposed in [13] or [10]. A competency is still described as a simple "label", i.e. an entry in a competence list, where each competency is characterised by a quantitative

${ }^{12}$ We have not listed the numerous commercial software tools dealing with "competence management", these products being mainly dedicated to the Human Resources departments and hardly able to make a link between competence and industrial processes. 
Final draft paper published in : Computers in industry, Volume 58, Issue 2, February 2007, Pages 98-117

evaluation. Such a list is used as input-data to generate decision-making support but the reliability of such initial data is questionable: what are the components to be considered to proceed to the quantitative evaluation of competencies (notably the technological context is generally not considered although it has a great impact). Very often, the competence evaluation procedure is neither systematic nor context-independent.

There are already tangible advances on decision-support methods and tools concerning the management of individual competence or global competence of the firm. However, research on the management of collective competence is less developed. Several papers identified on this issue (see Table 2) show that it represents a topical point, and that collective competence cannot of course be reduced to a simple sum of individual competencies. However, the way to integrate it within industrial engineering methods remains an open question, on the frontier between qualitative and quantitative methods of performance management: should collective competence only be considered from the field of qualitative socio-human-managerial approaches, or can it be also partially integrated in more quantitative methods of industrial management?

This weakness concerning collective competencies also underlines a lack of integration between the various levels of competence management. Indeed, the decision-makers use different types of methods depending on their point of view:

- Top-down methods are used for a consistent deployment of strategic orientations through collective and then individual competencies;

- bottom-up methods are used to simulate performance of operational processes with regards to available competencies and in order to optimise improvement or change scenarios.

To ensure consistence between these complementary decision areas, a recursive approach is necessary, based on a multi-level structuring of decision systems in a way to support process performance and to allow relevant competence enhancement. The management of organisation is becoming ever more complex and it requires global and interconnected visions of process and competence management. Mapping tools should provide decision-makers with better visualisation of the distribution of competencies from the global level down to individual competencies. More formalised models and computer-based tools remain necessary in this field.

At the beginning of the paper (section 2) a static view and a dynamic view of competencies were identified. So far, there has been a clear-cut separation between the two views, and the notion of competence dynamics is hardly ever considered in formal approaches, notably concerning the configuration or the simulation of processes. There is certainly a great challenge in being able to anticipate qualitative and quantitative evolutions of competencies (increase as well as decrease). Formal models of competence dynamics will be necessary before 
Final draft paper published in : Computers in industry, Volume 58, Issue 2, February 2007, Pages 98-117

being able to integrate this dynamic view into performance management tools. First intents can be found in [121] with a model focusing on means of action for competence development, in [25] with the simulation of the evolution of competence levels over time and their impact on process performances, or in [92] with the development of competencies for distributed organisations. The anticipation of competencies evolutions and their impact on the performance also aims at managing both a short term and long term vision of the performance.

Many other specific perspectives could be detailed concerning respectively sections 3,4 or 5 . However as a final conclusion we emphasise only one last common perspective which appears transversal: the link between competence and risk management.

- In the management of design projects, companies not only manage design projects, but also portfolios of projects. The ability to evaluate risks and to choose the most relevant orientations of innovation becomes strategic. Such ability is directly linked to the capacity of identifying and evaluating competencies, as well as to the capacity to anticipate or induce changes of competencies.

- In production management, models of skills/abilities make it possible to get a quantified identification of critical competencies for the performance of processes.

- Concerning distributed organisations cooperation between firms always induces volunteer or un-desired transfers of knowledge or competencies. High risks are underlined in the economic literature: risk of bad competence trajectory, risk of competence obsolescence, risk of unbalanced profit between partners, etc.

We have not found yet any formal method to cope with such risks and to provide the managers with decisionmaking assistance. This risk evaluation requires both a static vision (identification of risks in a given situation) and an anticipative vision (potential risks in the future). These risks are often linked to socio-human factors, which certainly requires taking into account social theories, as underlined in [103].

\section{Acknowledgment}

We would like to thank Pr. F. Vernadat for his recommendations and contributions to the final version of this paper.

\section{References}

[1] Zarifian P., Le modèle de la compétence. Trajectoire historique, enjeux actuels et propositions, Editions Liaisons, Paris, 2001. 
Final draft paper published in : Computers in industry, Volume 58, Issue 2, February 2007, Pages 98-117

[2] Porter M. E., L'avantage Concurrentiel Des Nations, Paris, Intereds, 1993.

[3] Wernerfelt, B., A Resource-Based View of the Firm, Strategic Management Journal, 5, 171-180, 1984.

[4] Sanchez, R., A. Heene and H. Thomas, Dynamics of Competence-based Competition, Elsevier, 1996.

[5] Quelin B., Arregle J. L., Le Management Stratégique Des Compétences, Editions Ellipses, 2000.

[6] Boucher X., Burlat P., Vers l'intégration des compétences dans le pilotage des performances de l'entreprise, Journal Européen des Systèmes Automatisés (JESA), 37(3), 363-390, 2003.

[7] Berrah L., Vernadat F., Perception et evaluation de la performance dans le pilotage, in (P. Pujo, JP. Kieffer, Eds.) Fondements du pilotage des systèmes de production, Editions Hermès, Paris, 2002, Chap. 6, pp. 181-203.

[8] Harzallah M., Modélisation des aspects organisationnels et des compétences pour la réorganisation d'entreprises industrielles, PhD thesis, University of Metz, France, May 2000.

[9] Jia T., Vers une meilleure gestion des ressources d'un groupe autonome de fabrication, $\mathrm{PhD}$ thesis, Tours University, Dec. 1998.

[10] Franchini L., Aide à la décision pour la gestion des opérateurs en production: modélisation, planification et évaluation, PhD. Thesis, Toulouse University, France, 2000.

[11]Pepiot G., Cheikhrouhou N., Furbringer J.M., Glardon R., A fuzzy approach for the valorization of the competencies, International Conference on Industrial Engineering and Systems Management, IESM 2005, May 16-19, Marrakech, Marrocco, 2005.

[12] Cannavacciuolo A., Capaldo G., Ventre A., Volpe A. Zollo, G., A fuzzy model of evaluation process, Fuzzy Systems, Proc. Fifth IEEE International Conference on Digital Object, 2, Sept. 8-11, pp. 828 - 834, 1996.

[13] Harzallah M, Berio G, Vernadat F. Analysis and modeling of individual competencies : toward better management of human resources, IEEE Transactions on Systems, man, and Cybernetics-PART A: Systems and Humans, Vol. 36, N¹, January 2006.

[14] Grabot B., Letouzey A., Short term manpower management in manufacturing systems: new requirements and DSS prototyping, Computers in Industry, 43, 11-29, 2000.

[15]El Mhamedi A., Sur l'intégration des aspects humains dans la conduite multi-niveaux d'ateliers de production, PhD. Thesis, INPG, Grenoble, France, 1990.

[16] Plekhanova V., Capability and Compatibility measurement in software process improvement, $2^{\text {nd }}$ European software measurement conference, FESMA'99, October 4-8, Amsterdam, Netherlands, 1999.

[17] Borbrowski P.M., Park P.S., An evaluation of labour assignment rules when workers are not perfectly interchangeable, International Journal of Operation Management, 11 (3), 257-268, 1993.

[18] Rasmussen J., "Skills, Roles, and knowledge: Signals, Signs, and Symbols, and other Distinctions in Human Performance Models”, IEEE Trans. on Systems, Man, and Cybernetics SMC-13(3), May/June, 1983.

[19] Yu Li, Biqing Huang, Wenhuang Liu, Hongmei Gou, Cheng Wu, “Ontology for modeling and analyzing of enterprise competence”, Systems, Man, and Cybernetics, IEEE International Conference on Digital Object Identifier, Volume 5, 7-10 Oct. 2001, pp $2941-2946$.

[20]Zülch G., Grobel T., Shaping the organization of order processing with the simulation tool FEMOS, International Journal of Production Economics, 46-47, 251-260, 1996.

[21] Arditi D., Tokdemir K. Suh, Effect of learning on line balancing scheduling, International Journal of Project Management, 19, 236-277, 2001.

[22] Mosheiov G., Scheduling problem with learning effect, European Journal of Operational Research, 13, 687-693, 2001.

[23]Loven E.M., Helander, M.G., "Effect of operator competence on assessment of quality control in manufacturing", Industrial Journal of Industrial Ergonomics, 19, 307-316, 1997.

[24] Coves C., Analyse et estimation des performances de processus d'entreprise, PhD. Thesis, University Montpellier II, France, Dec. 2000.

[25] Bennour M., Crestani D., Prunet F., Intégration des compétences individuelles et collectives dans le calcul des performances de processus, Proc. 1st national meeting Gestion des Compétences et des Connaissances en Génie Industriel, Vers l'articulation entre Compétences et Connaissances, Nantes, France, Dec. 12-13, 2002. 
Final draft paper published in : Computers in industry, Volume 58, Issue 2, February 2007, Pages 98-117

[26]Fawcet S.E., Calantone R., Smith S.R. Delivery capability and firm performance in international operations, International Journal of Production Economics, 51, 191-204, 1997.

[27]Zhang Q., Vonderembse M.A., Lim J.S., Manufacturing flexibility: defining and analyzing relationships among competence, capability, and customer satisfaction, Journal of Operation Management, 21, 173-191, 2003.

[28]Lloréns F. J., Molina L.M. and Verdú A.J., Flexibility of manufacturing systems, strategic change and performance, International Journal of Production Economics, 2004. Please, complete reference

[29]Perona M., Miragliotta G., Complexity management and supply chain performance assessment. A field study and a conceptual framework, International Journal of Production Economics, 90, 103-115, 2004.

[30] Narasimhan R., Talluri S., Das A., Eploring flexibility and execution competencies of manufacturing firms, Journal of Operation Management, 22, 91-106, 2004.

[31] White G.P., A meta analysis model of manufacturing capabilities, Journal of Operation Management, 14 , 315-331, 1996.

[32]DeCarolis M.D., Competencies and Imitability in the Pharmaceutical Industry: an analysis of their relationship with firm performance, Journal of Management, 29 (1), 27-50, 2003.

[33] Walsh S., Linton J.D., The measurement of technical competencies, Journal of high technology management research, 13, 63-86. 2002.

[34] St John Caron H., Pouder R. W., Cannon A. R., Environmental Uncertainty and Product Process Life Cycles: A Multi-level Interpretation of Change Over Time, Journal of Management Studies, 40(2), 513, 2003.

[35]Lewis M. A., Success, failure and organisational competence: a case study of the new product development process, Journal of Engineering and Technology Management, 18(2), 185-206, 2001.

[36] Torkkeli M, Tuominen M, The contribution of technology selection to core competencies, International Journal of Production Economics, 77, 271-284, 2002.

[37] Sazonova G.A., Kolishchak A.N., Management of technological changes and innovations as a core competence, Proc. IEEE International Engineering Management Conference, Vol. 1, 18-21 Oct., pp. 407 - 411 , 2004.

[38] Rajczi L, A portfolio approach to managing technological innovations, IEEE Technology Management: the New International Language, 27-31 Oct., pp 640 - 643, 1991.

[39] Dawson K, Core competency management in R\&D organizations, IEEE Technology Management: the New International Language, 27-31 Oct., pp 145 - 148, 1991.

[40] Lartigue N., Knowledge and design, Proc. International Congress - SIA- Poissy, France, 17-18-September, 2003.

[41] Osterlund J, Competence management by informatics in R\&D: The corporate level, IEEE Transactions on Engineering Management, 44 (2), 135-145, 1997.

[42] Kusiak A, Park K, Concurrent design: decomposition of design activities, Proceedings of Rensselaer's Second International Conference on Computer Integrated Manufacturing, 21-23 May, pp 557-563, 1990.

[43] Chen S.-J., Lin L., Decomposition of interdependent task group for concurrent engineering, Computers and Industrial Engineering, 44, 435-459, 2003.

[44] Eriksson Ml; Lilliskold J., Project management competence requirements when procuring complex systems, IEEE international engineering management conference, Cambridge, United Kingdom, pp. 459-464, 2002.

[45]Bstieler L, The moderating effect of environmental uncertainty on new product development and time efficiency, Journal of Product Innovation Management, 22 (3), 267-284, 2005.

[46] Mc Dermott C.M, O' Connor G.C, Managing radical innovation: an overview of emergent strategy issues, Journal of Product Innovation Management, 19 (6), 424-438, 2002.

[47] Herroelen W., Leus R., Project scheduling under uncertainty: Survey and research potentials, European Journal of Operational Research, 165,(2), 289-306, 2005.

[48] Belbin R.M., Management teams: why they success or fail, Heinemann, London, 1981. 
Final draft paper published in : Computers in industry, Volume 58, Issue 2, February 2007, Pages 98-117

[49] Stickley A., Grabot B., Fuzzy Logic in Team Design, IFIP WG 5.7 Conference - Benchmarking theory and practice, Trondheim, June 16-18, 1994.

[50] Sommerville J., Dalzel S., Project Teambuilding the applicability of Belbin's team role self-perception inventory, International Journal of Project Management, 16(3), 165-171, 1998.

[51]Hadj-Hamou K., Caillaud E., Cooperative Design: A Framework for a Competency-Based Approach, Proc. Conf. IDMME, Bath, UK, April 5-7, 2004.

[52]Kichuk S.L., Wiesner W.H., The big five personality factors and team performance: implications for selecting successful product design teams, Journal of Engineering and Technology Management, 14, 195-221, 1997.

[53]Zakarian, A. and Kusiak, A., "Forming Teams: An Analytical Approach," IIE Transactions on Design and Manufacturing, vol. 31, no. 1, pp. 85-97, 1999.

[54] Trower J. K. and Moore K. K., Study of the impact of individual goals and team composition variables on team performance, Proc. ACM SIGCPR Conf., New York, pp. 206-213, 1996.

[55] Chen S.-J., Lin L., Modeling Team Member Characteristics for the Formation of a Multifonctional Team in Concurrent Engineering, IEEE Transactions on Engineering Management, 51(2), May, 2004.

[56] Acuna ST, Juristo N, Assigning people to roles in software projects, Software, Practice and Experience, 34 (7), 675-696, 2004.

[57] Tsai H-T., Moskowitz H., Lee L-H., Human resource selection for software development projects using Taguchi's parameter design, European Journal of Operational Research, 151, 167-180, 2003.

[58]De Korvin A, Shipley M.F, Kleyle R, Utilizing fuzzy compatibility of skill sets for team selection in multiphase projects, Journal of Engineering Technology Management, 19, 307-319, 2002.

[59]Lang, A., Pigneur, Y., Digital trade of human competencies, Proceedings of the 32nd Annual Hawaii International Conference on System Sciences, Volume Track 5, 5-8 Jan., 1999.

[60] Shen W (Ed.), Knowledge Sharing in Collaborative Design Environments, Computers in Industry, 52(1), 193, 2003.

[61] Madhusudan T., An agent-based approach for coordinating product design workflows, Computers in Industry, 56 (3), 235-259, 2005.

[62]Zhu Y, Tong F, Soenen R, General issues on multi-agent system supporting the decisions in collaborative design, Proc. IEEE Conference on Systems, Man, and Cybernetics, 2002.

[63] Lee C-H, Sause R., Hong N. K., Overview of entity-based integrated design product and process models, Advances in Engineering Software, 29(10), 809-823, 1998.

[64] Rodriguez K. and Al-Ashaab A., Knowledge web-based system architecture for collaborative product development, Computers in Industry, 56(1), 125-140, 2005.

[65] Boujut J.F., Laureillard P., A co-operation framework for product-process integration in engineering design, Design Studies, 23, 497-513, 2002.

[66] Perry M., Sanderson D., Coordinating joint design work: the role of communication and artefacts, Design Studies, 19, 273-288, 1998.

[67] Segrestin B., Lefèbvre P., Weil B., The role of design regimes in the coordination of competencies and the conditions for inter-firm cooperation, International Journal of Automotive, Technology and Management, 2 (1), 63-83, 2002.

[68] Von Zedtwitz M, Post project reviews in R\&D, Research Technology Management, 46 (5), 43-49, 2003.

[69] Michael S.C.; Palandjian T.P., Organizational learning and new product introductions, Journal of Product Innovation Management, 21 (4), 268-276, 2004.

[70] Winston W.L., Introduction to Mathematical Programming, Second Edition, Duxbuy Press, Belmont, California, 1995.

[71] Ernst A.T., Jiang H., Krishnamoorthy M., Sier D., Staff scheduling and rostering: a review of applications, methods and models, European Journal of Operation Research, 153, 3-27, 2004. 
Final draft paper published in : Computers in industry, Volume 58, Issue 2, February 2007, Pages 98-117

[72] Bard J.F., Selecting the appropriate input data set when configuring a permanent workforce, Computers and Industrial Engineering, 47, 371-389, 2004.

[73]Bard J.F., Binici C., deSilva A.H., Staff scheduling at the United States Postal Service, Computers and Operations Research, 30, 745-771, 2003.

[74] Judice J., Martins P., Nunes J., Workforce planning in a lotsizing mail processing problem, Computers and Operations Research, 32, 3031-3058, 2005

[75] Moz M., Vaz Pato M., A genetic algorithm approach to nurse rerostering problem, Computers and Operations Research, available online at www.sciencedirect.com, 2005.

[76]Lee T., The effect of workers with different capabilities on customer delay, Computers and Operations Research, 31, 359-381, 2004.

[77]Hur D., Mabert V.A., Bretthauer K., Real-time schedule adjustment decisions: a case-study, Omega, 32, 333-344, 2004.

[78]Cheang B., Li H., Lim A., Rodrigues B., Nurse rostering problems - a bibliographic survey, European Journal of Operational Research, 151, 447-460, 2003.

[79] Qi X., Bard J.F., Generating labor requirements and rosters for mail handlers using simulation and optimization, Computers and Operations Research, to be published, available online at www.sciencedirect.com, 2005.

[80] Hwang N., Kogan K., Dynamic approach to human resources planning for major professional companies with a peak-wise demand, International Journal of Production Research, 41(6), 1255-1271, 2003.

[81] Bard J.F., Purnomo H.W., A column generation-based approach to solve the preference scheduling problem for nurses with downgrading, Socio-Economic Planning Sciences, 39, 193-213, 2005.

[82] Cai X., Li K.N., A genetic algorithm for scheduling staff of mixed skills under multi-criteria, European Journal of Operational Research, 125, 359-369, 2000.

[83] Cochran J.K., Chu D.E., Chu M.D., Optimal staffing for cyclically scheduled processes, International Journal of Production Research, 35(12), 3393-3403, 1997.

[84] Franchini L., Caillaud E., Nguyen P., Lacoste G., Workload control of human resources to improve production management, International Journal of Production Research, 39(7), 1385-1403, 2001.

[85] SAP, SAP R/3 Enterprise - Documentation, CD-Rom, 2003.

[86]Buzacott J.A., The impact of worker difference on production system output, International Journal of Production Economics, 78(1), 37-44, 2002.

[87]Nembhard A.D., Osothsilp N., Task complexity effects on between-individual learning/forgetting variability, International Journal of Industrial Ergonomics, 29(1), 297-306, 2002.

[88]Hannoun M. and Guerrier G., Le partenariat industriel, Ministère de l'Industrie, Direction Générale des Statistiques Industrielles, SESSI, Paris, 1996.

[89] Lackenby, C., Seddighi H., A dynamic model of virtual organisations: formation and development, Proc. $3^{\text {rd }}$ Working Conference on Infrastructures for Virtual Enterprises (PROVE'02), May 1-3, Sesimbra, Portugal, pp 37-44, 2002.

[90] Walton J., Whicker, 1996, "Virtual Enterprise: myth and reality". Journal of Control, Volume??, 22-25, 1996.

[91] Tuma, A. Configuration and coordination of virtual production networks, International Journal of Production Economics, 56-57, 641-648, 1998.

[92] Boucher X., Lebureau E., Coordination of competencies development within networks of SMEs, Proc. 6th IFIP Working Conference on Virtual Enterprises (PRO-VE'05), Virtual Enterprise and Collaborative Network, 26-28 Sept. 2005, Valencia, Spain.

[93] Peillon S., Le pilotage des coopération interentreprises: le cas des groupement de PME. PhD thesis, Ecole Nationale Supérieure des Mines de Saint Etienne, Oct. 2001.

[94] Camarinha-Matos L.M., Afsarmanesh, Further developments in Virtual Enterprises, Proc. $1^{\text {st }}$ IFIP Conference on Infrastructures for Virtual enterprises: Networking industrial Enterprises, October 27-28, Porto, Portugal, 1999. 
Final draft paper published in : Computers in industry, Volume 58, Issue 2, February 2007, Pages 98-117

[95]Brouthers K.D., Brouthers L.E., Wilkinson T.J., Strategic Alliances: Choose Your Partner, Long Range Planning, 28, 18-25, 1995.

[96] Medcof J.W., Why do many alliances end in divorce, Long Range Planning, 30, 718-732, 1997.

[97]Pedersen J. D., Van den Berg T.J., Supporting partner selection for virtual enterprises, in Global Engineering, Manufacturing and Enterprise Networks (J.M.I. Nemes, Ed.), Kluwer, pp 95-102, 2001.

[98] Manthou V., Vlachopoulou M., Folinas D. Virtual a-Chain model for supply chain collaboration, International Journal of Production Economics, 87(3), 241-250, 2004.

[99] Grecopme, 2003, under coordination of Burlat P., GRECOPME II: GRoupements d'Entreprises COopérantes, Potentialités, Moyens, Evolutions, Final report, March 2003.

[100] Vesterager J., Tolle M., and Bernus P., Virtual Enterprise Reference Architecture, GLOBEMEN Book, Iris Karvonen, VTT Industrial Systems, Finland, 2002.

[101] Voster project (2001-2004), VO Modelling Report (2003)', Deliverable D24.1 at http://cic.vtt.fi/projects/voster/

[102] Fürbringer J.M., Glardon R., Glardon F., Pépiot G., Méthodologie COMET pour une Gestion Proactive des Compétences, $2^{\text {nd }}$ working group meeting C2EI, Modélisation et pilotage de systèmes de Connaissances et de Compétences dans les Entreprises Industrielles, 1-2 December, Nancy, France, 2004.

[103] Camarinha-Matos L.M., New collaborative organizations and their research needs, Fourth Working Conference on Virtual Enterprises (PROVE'03), October 29-31, Lugano, Switzerland, 2003.

[104] Petersen S.A., Agent based approach to support the formation of virtual enterprise, PhD thesis, Norwegian University of Science and Technology, 2003.

[105] Lee W.B., Lau H.C.W., Multi-agent modeling of dispersed manufacturing networks, Expert Systems with Applications, 16, 296-306, 1999.

[106] Neubert R., Görtlitz O., Teich T.,Automated negociation of supply contracts for flexible production networks, International Journal of Production Economics, 89, 175-187, 2004.

[107] Hammami A., Burlat P., Campagne J.P., Evaluationg orders allocation within networks of firms, International Journal of Production Economics, 86, 233-249, 2003.

[108] Fischer M., Jähn H., Teich T., Optimizing the selection of partners in production networks, Robotics and Computer-Integrated Manufacturing, 20, 593-601, 2004.

[109] Szegheo, O., Petersen, S.A.: Extended Enterprise Engineering - a model-based framework, Journal of Concurrent Engineering: Research and Applications, 8, 32-39, 2000.

[110] A.Zaidat, X.Boucher, L.Vincent, "A framework for organization network engineering and integration”, Robotics and Computer Integrated Manufacturing, 21 (2005), pp 259-271

[111] Tsakopoulos S., Bokma A., Plekhanova V., Partner evaluation and selection in virtual enterprises using a profile theory based approach, Fourth Working Conference on Virtual Enterprises (PROVE'03), October 2931, Lugano, Switzerland, 2003.

[112] Burlat P., Besombes B., Deslandres V., Constructing a typology for networks of firms, Production Planning and Control, 14(5), 399-409, 2003.

[113] Benali M., Burlat P., Methodology to analyze organizational trajectories of SMEs networks, Proc. Management Control and Production Logistics (MCPL 04) Conference, 3-5 Novembre, Santiago (Chili), pp. 25$32,2004$.

[114] Williams T.J., Li H., Bernus P., Uppington G., and Nemes L., The Life Cycle of an Enterprise. In Handbook of Life Cycle Engineering: Concepts, Tools and Techniques, (A. Molina, J.M. Sanchez, A. Kusiak, Eds.), Chapman \& Hall, London, 1998.

[115] Erbe H.H., Learning for agile manufacturing, IFIP TC5 Proceedings of the International Conference on Human Aspects in Production Management, 5-9 Oct. 2003.

[116] Nullmeier E., Personalentwicklung für informationstechisch vernetzte Arbeit, FH-Technik and Wirtschaft Magazin, Berlin, pp. 141-144, 2000. 
[117] Gerber A., Dietzsch M., Althaus K., Information based, dynamic information system for nonhierarchical regional production networks, Robotics and Computer-Integrated Manufacturing, 20, 583-591, 2004.

[118] Orlikowski W. J., Knowing in practice: Enacting a Collective Capability in Distributed Organizing, Organization Science, 13 (3), 249-273, 2002.

[119] Boekhoff, H., Erbe H.H., Organisationales Lernen: kritischer Erfolgsfaktor für virtuelle Unternehment?, Industrie Management, 15 (6), 13-16., 1999.

[120] Bowersox D.J., Closs D.J., Theodor P.S., How to aster cross-enterprise collaboration, Supply Chain Management Review, July-August 2003.

[121] Bonjour E., Dulmet M., Lhote F., "Models to split and to integrate competencies systems in design activities management", Proc. 11th Symposium on INformation COntrol in Manufacturing, IFAC, INCOM'2004, Salvador de Bahia, Brazil, 2004. 
Final draft paper published in : Computers in industry, Volume 58, Issue 2, February 2007, Pages 98-117

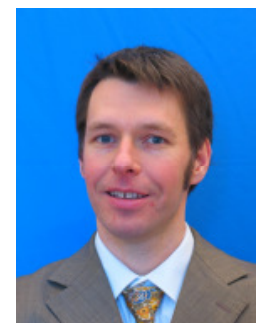

Xavier Boucher received the $\mathrm{PhD}$ degree in industrial management in 1999 from AixMarseille University, France, for its research on concurrent engineering methodology. He is currently Assistant-Professor in production management at the Ecole nationale supérieure des mines de Saint Etienne. In the French scientific community of production management, he has been member of the national normalization group AFNOR X50-184 on management of competencies, and co-responsible of a French national CNRS workgroup on modeling and management of competencies' systems. He has published in Concurrent Engineering : Research and Application, Robotics and Computer Integrated Manufacturing, International Journal of Design Sciences and Technology, Journal Européen des Systèmes Automatisés. His actual research focuses on the integration of socio-technical systems, with two main orientations: the management of multi-enterprises systems of competencies, including the decision support required at distinct management levels and the development of methodological approaches to manage the evolution of information systems.

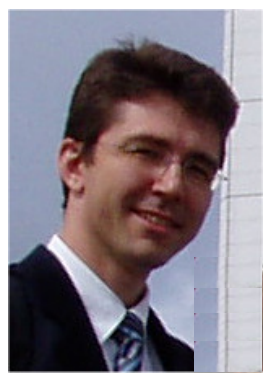

Eric Bonjour is a lecturer at the University of Franche-Comté and is a member of the LAB laboratory in Besançon (France). He has been a mechanical engineer since 1993. He received his $\mathrm{PhD}$ degree in Automation and Industrial Engineering in 1996. His research projects aim at developing methods and tools to assist the activities of project managers and architects who design complex products. Since 2000, he has been leading a research project involving 6 researchers in collaboration with a French car manufacturer. This project concerns the modelling and the management of engineering competencies mobilised in new product development projects (in particular, a car engine and a robotized gearbox). He has published more than 30 papers for conferences, journals and books.

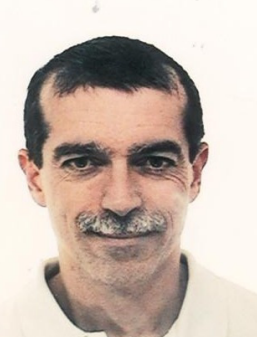

Bernard Grabot is Professor in the National Engineering School of Tarbes (ENIT), France where his main courses are oriented on Production Management and Information Systems. His research interests are mainly oriented on Planning and Scheduling, Supply Chain Management, Competence Management and ERP systems. Pr. Grabot is the Deputy Editor in Chief of the IFAC international journal "Engineering Applications of Artificial Intelligence", and member of the IFAC technical committees on "Cognition and Control" and "Manufacturing Plant Control". 


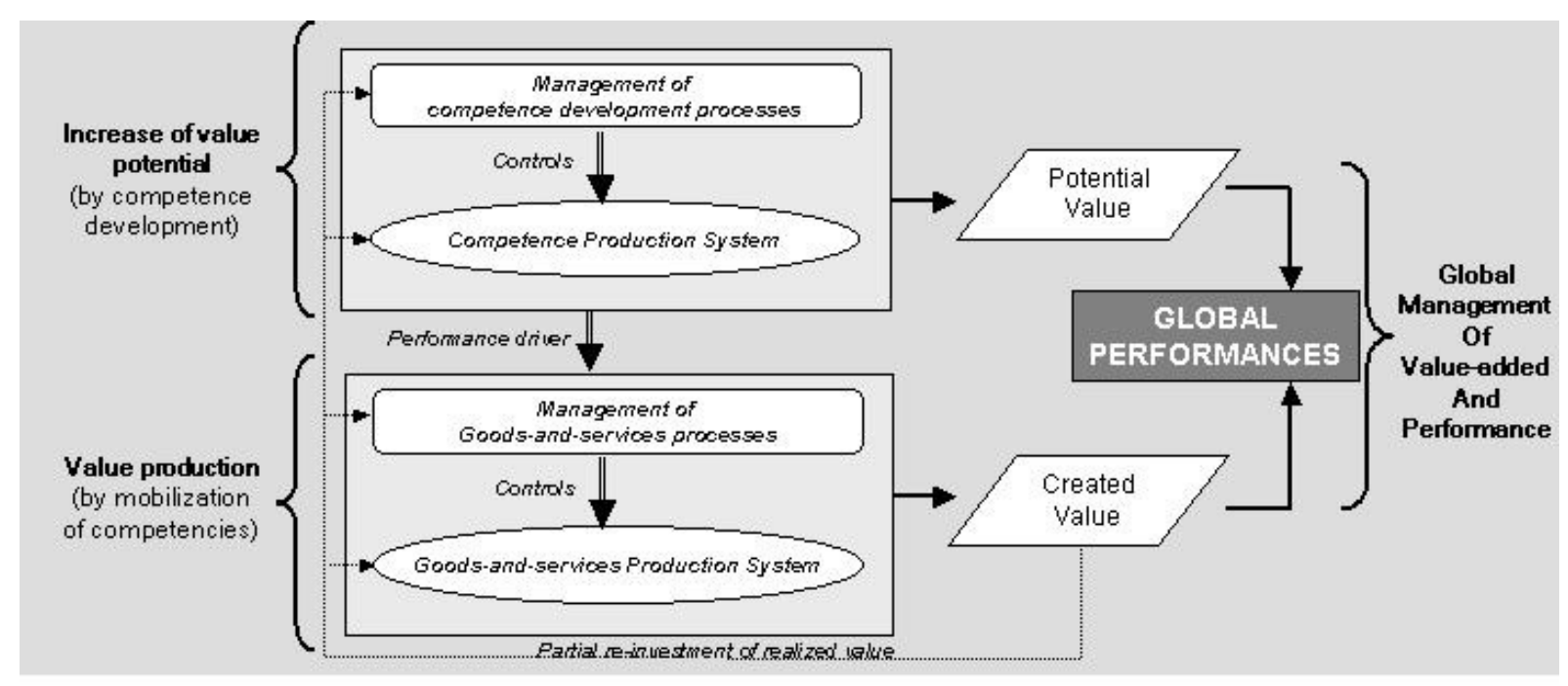

Figure 1. Two complementary points of view on performance according to Boucher and Burlat [6] 
Final draft paper published in : Computers in industry, Volume 58, Issue 2, February 2007, Pages 98-117

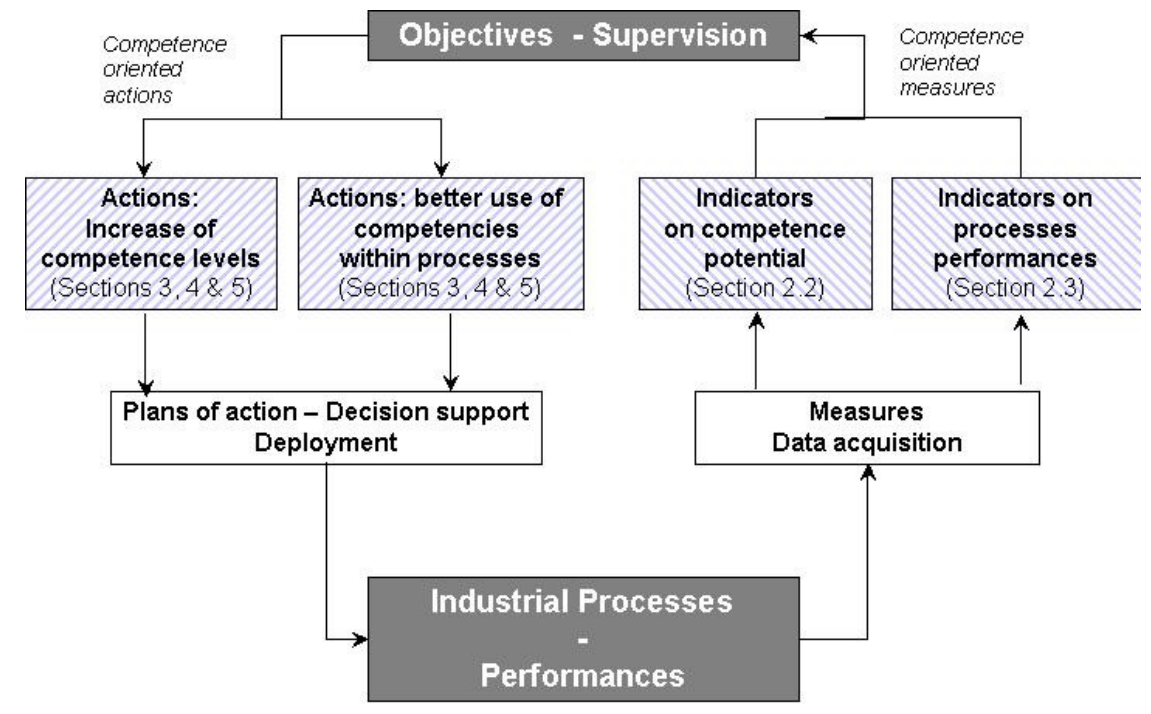

Figure 2. Two types of indicators and means of action 
Final draft paper published in : Computers in industry, Volume 58, Issue 2, February 2007, Pages 98-117

\begin{tabular}{|c|c|c|c|}
\hline & Structural view & Functional view & Evolution view \\
\hline & \multicolumn{3}{|c|}{ Competence-based strategic management } \\
\hline Strategic & $\begin{array}{l}\text { - Identification of core } \\
\text { competencies at the } \\
\text { enterprise level } \\
\text { - Objective definition } \\
\text { (Definition of strategy) }\end{array}$ & $\begin{array}{l}\text { - Deployment of strategy } \\
\text { through collective } \\
\text { competencies } \\
\text { - Inter-firms relationship } \\
\text { management }\end{array}$ & $\begin{array}{l}\text { - Competencies trajectory, } \\
\text { adapted to new technological } \\
\text { orientations (technology, } \\
\text { tools, methods, ...) } \\
\text { - (Networked) firms' life cycle } \\
\text { management }\end{array}$ \\
\hline Tactical & $\begin{array}{l}\text { - Identification of } \\
\text { available } \\
\text { competencies } \\
\text { - Competence } \\
\text { evaluation } \\
\text { - Analysis "strengths } \\
\text { and weaknesses" on } \\
\text { processes }\end{array}$ & $\begin{array}{l}\text { - Team building } \\
\text { - Competence allocation } \\
\text { (task assignment) } \\
\text { - Competency-based } \\
\text { process simulation } \\
\text { - Partners selection in } \\
\text { distributed organizations } \\
\text { - Competence oriented } \\
\text { risks management }\end{array}$ & $\begin{array}{l}\text { - Anticipation of competence } \\
\text { evolutions (new roles, new } \\
\text { requirements,...) } \\
\text { - Formal models of } \\
\text { competence dynamics } \\
\text { - Action plans to develop } \\
\text { competence }\end{array}$ \\
\hline Operational & \multicolumn{2}{|c|}{$\begin{array}{l}\text { - Local vision on operational performances } \\
\text { - psychological and social mecanisms : mobilisation } \\
\text { mecanisms, autonomy, reactivity, mutual } \\
\text { adjustments,... }\end{array}$} & $\begin{array}{l}\text { - learning by doing, } \\
\text { knowledge explicitation or } \\
\text { acquisition, new management } \\
\text { practices } \\
\text { - education, training }\end{array}$ \\
\hline
\end{tabular}

Table 1. Positioning of the survey 
Final draft paper published in : Computers in industry, Volume 58, Issue 2, February 2007, Pages 98-117

\begin{tabular}{|c|c|c|c|c|c|c|}
\hline & \multicolumn{4}{|c|}{ Research contributions } & \multicolumn{2}{|c|}{ Applications } \\
\hline & $\begin{array}{l}\text { Specification of } \\
\text { Concepts / } \\
\text { Descriptive Model }\end{array}$ & \begin{tabular}{|l|} 
Structured \\
method based on \\
qualitative \\
model
\end{tabular} & $\begin{array}{l}\text { Formalised model } \\
\text { linked to decision } \\
\text { support system }\end{array}$ & $\begin{array}{l}\text { Formal model } \\
\text { linked to } \\
\text { another type } \\
\text { of application }\end{array}$ & Case study & $\begin{array}{l}\text { Tools aiming at } \\
\text { a professional } \\
\text { use in } \\
\text { companies }\end{array}$ \\
\hline $\begin{array}{l}\text { Individual } \\
\text { competence }\end{array}$ & $\begin{array}{l}552] \text { Kichuk and } \\
\text { Wiesner, } 1997\end{array}$ & $\begin{array}{l}\text { [13] Harzallah et } \\
\text { al., 2006 } \\
\text { [23] Loven and } \\
\text { Helander, } 1997 \\
\text { [24] Coves, 2000 } \\
\text { [102] Fürbringer } \\
\text { et al., 2004 }\end{array}$ & $\begin{array}{l}\text { [13]Harzallah et al., } \\
2006 \\
\text { [10] Franchini, 2000 } \\
\text { [11] Pepiot et al. } \\
\text { 2005 } \\
\text { [12] Cannavacciuolo, } \\
1996 \\
\text { [14] Grabot and } \\
\text { Letouzey, 2000 } \\
\text { [21] Arditi and Suh, } \\
\text { 2001 } \\
\text { [22]vMosheiov, 2001 } \\
\text { [24] Coves, 2000 } \\
\text { [72] Bard, 2004 } \\
\text { [79] Qi and Bard, } \\
\text { 2005 }\end{array}$ & & $\begin{array}{l}\text { [8] Harzallah, } \\
2000 \\
\text { [10] Franchini, } \\
2000 \\
\text { [24] Coves, } 2000 \\
\text { [14] Grabot and } \\
\text { Letouzey, } 2000\end{array}$ & $\begin{array}{l}\text { [11] Pepiot et } \\
\text { al., } 2005\end{array}$ \\
\hline $\begin{array}{l}\text { Collective } \\
\text { competence } \\
\text { (Groups) }\end{array}$ & $\begin{array}{l}\text { [52] Kichuk and } \\
\text { Wiesner, } 1997 \\
\text { [40] Lartigue, } 2003 \\
\text { [66] Perry and } \\
\text { Sanderson, } 1998 \\
\text { [67] Segrestin et al., } \\
2002\end{array}$ & $\begin{array}{l}\text { [48]Belbin, } \\
\text { 1981 } \\
\text { [56] Acuna and } \\
\text { Juristo , } 2004\end{array}$ & $\begin{array}{l}\text { [58] De Korvin } \text { et al., } \\
\text { 2002 } \\
\text { [59] Lang and } \\
\text { Pigneur, 1999 } \\
\text { [62] Zhu et al., 2002 } \\
\text { [55] Chen and Lin, } \\
\text { 2004 } \\
\text { [51] Hadj-Hamou and } \\
\text { Caillaud, 2004 } \\
\text { [9] Jia, 1998 } \\
\text { [57] Tsai } \text { et al., 2003 } \\
\text { [15] ElMhamedi, } 1990 \\
\text { [25] Bennour et al., } \\
\text { 2002 } \\
\text { [82] Cai and Li, } 2000\end{array}$ & $\begin{array}{l}65] \text { Boujut } \\
\text { and } \\
\text { Laureillard, } \\
2002 \\
{[61]} \\
\text { Madhusan, } \\
2005\end{array}$ & $\begin{array}{l}\text { [65] Boujut and } \\
\text { Laureillard, 2002 } \\
\text { [58] De Korvin } \\
\text { et al., 2002 } \\
\text { [66] Perry and } \\
\text { Sanderson, } 1998 \\
\text { [9] Jia, 1998 } \\
\text { [15] ElMhamedi, } \\
\text { 1990 } \\
\text { [25] Bennour et } \\
\text { al., 2002 } \\
\text { [41] Osterlund, } \\
1997\end{array}$ & $\begin{array}{l}\text { [59] Lang and } \\
\text { Pigneur, } 1999\end{array}$ \\
\hline $\begin{array}{l}\text { Firm } \\
\text { competence } \\
\text { (Organisation) }\end{array}$ & $\begin{array}{l}\text { [89] Lackenby and } \\
\text { Seddighi, 2002 } \\
\text { [93] Peillon, 2001 } \\
\text { [99] Grecopme, 2003 } \\
\text { [26] Fawcet et al., } \\
\text { 1997 } \\
\text { [27] Zhang } \text { et al., } \\
\text { 2003 } \\
\text { [28] Llorens } \text { et al., } \\
\text { 2004 } \\
\text { [29]Perona and } \\
\text { Miragliotta, 2004 } \\
\text { [30] Narasimhan } \text { et } \\
\text { al., 2004 } \\
\text { [32] DeCarolis, 2003 } \\
\text { [97] Pedersen and } \\
\text { Van den Berg, 2001 } \\
\text { [120] Bowersox et al., } \\
\text { 2003 }\end{array}$ & $\begin{array}{l}\text { [91] Tuma, } 1998 \\
\text { [31] White, } 1996 \\
\text { [33] Walsh and } \\
\text { Linton, 2003 } \\
\text { [98] Manthou et } \\
\text { al., 2003 } \\
\text { [112] Burlat et } \\
\text { al., 2003 } \\
\text { [115] Erbe, } 2003\end{array}$ & $\begin{array}{l}\text { [92] Boucher and } \\
\text { Lebureau, 2005 } \\
\text { [104] Petersen,2003 } \\
\text { [105] Lee and Lau, } \\
1999 \\
\text { [106] Neubert et al., } \\
2004 \\
{[107] \text { Hammami et al., }} \\
2003 \\
{[108] \text { Fischer et al., }} \\
2004 \\
{[111] \text { Tsakopoulos et }} \\
\text { al., 03 } \\
{[113] \text { Benali and }} \\
\text { Burlat, 2004 }\end{array}$ & $\begin{array}{l}\text { [110] Zaidat } \\
\text { et al., 2005 } \\
\text { [109] Szegheo } \\
\text { et al., 2000 } \\
{[116]} \\
\text { Nullmeier, } \\
1999 \\
\text { [117] Gerber } \\
\text { et al., } 2004\end{array}$ & $\begin{array}{l}\text { [92] Boucher } \\
\text { and Lebureau, } \\
2005 \\
{[93] \text { Peillon }} \\
2001 \\
{[104]} \\
\text { Petersen,2003 } \\
{[111]} \\
\text { Tsakopoulos et } \\
\text { al., 03 } \\
\text { [105] Lee and } \\
\text { Lau, 1999 } \\
\text { [41] Osterlund, } \\
1997\end{array}$ & \\
\hline
\end{tabular}

Table 2. Positioning of the main contributions 